\title{
Moisture Durability Assessment of Selected Well-insulated Wall Assemblies
}

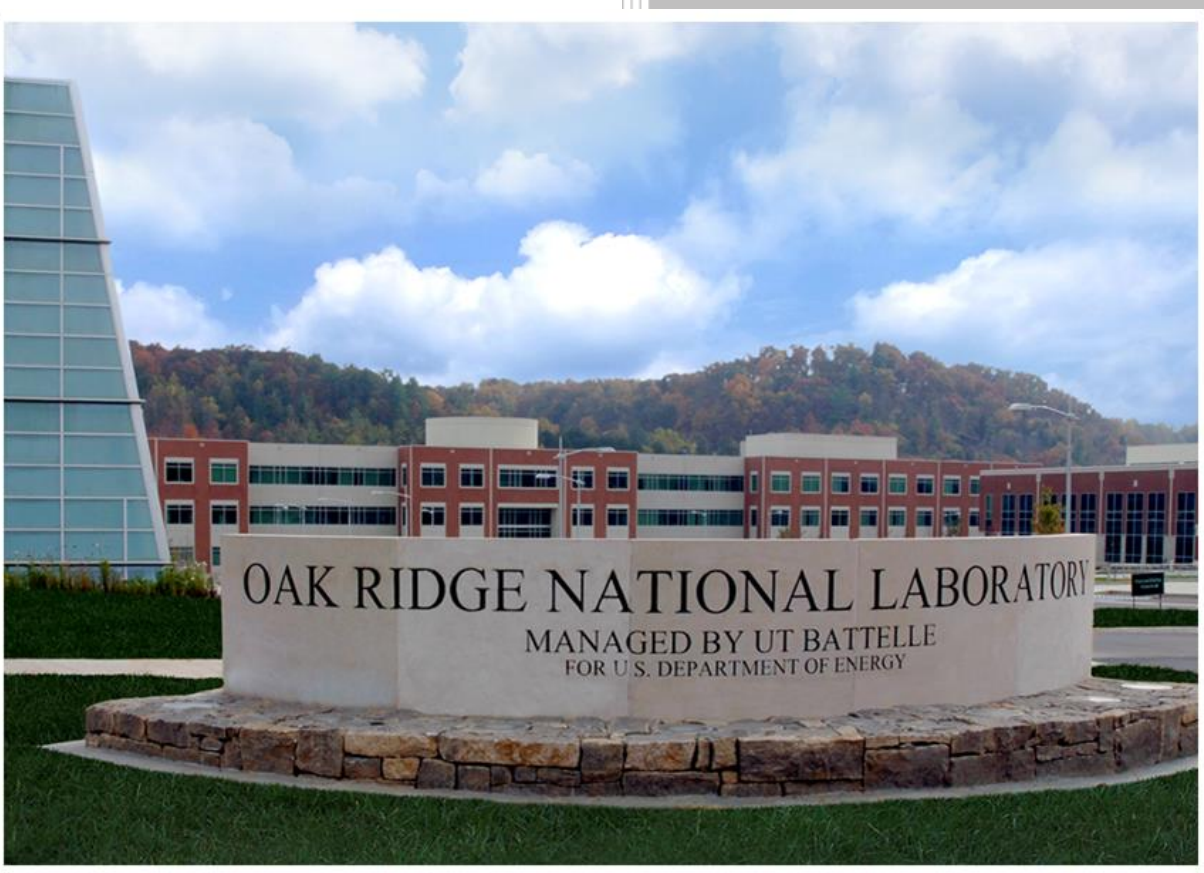

Simon Pallin, PhD Philip Boudreaux Manfred Kehrer Diana E. Hun, PhD Roderick K. Jackson, PhD André O. Desjarlais

December 2015 


\title{
DOCUMENT AVAILABILITY
}

Reports produced after January 1, 1996, are generally available free via US Department of Energy (DOE) SciTech Connect.

Website http://www.osti.gov/scitech/

Reports produced before January 1, 1996, may be purchased by members of the public from the following source:

\author{
National Technical Information Service \\ 5285 Port Royal Road \\ Springfield, VA 22161 \\ Telephone 703-605-6000 (1-800-553-6847) \\ TDD 703-487-4639 \\ Fax 703-605-6900 \\ E-mail info@ntis.gov \\ Website http://www.ntis.gov/help/ordermethods.aspx
}

Reports are available to DOE employees, DOE contractors, Energy Technology Data Exchange representatives, and International Nuclear Information System representatives from the following source:

Office of Scientific and Technical Information

PO Box 62

Oak Ridge, TN 37831

Telephone 865-576-8401

Fax 865-576-5728

E-mail reports@osti.gov

Website http://www.osti.gov/contact.html

This report was prepared as an account of work sponsored by an agency of the United States Government. Neither the United States Government nor any agency thereof, nor any of their employees, makes any warranty, express or implied, or assumes any legal liability or responsibility for the accuracy, completeness, or usefulness of any information, apparatus, product, or process disclosed, or represents that its use would not infringe privately owned rights. Reference herein to any specific commercial product, process, or service by trade name, trademark, manufacturer, or otherwise, does not necessarily constitute or imply its endorsement, recommendation, or favoring by the United States Government or any agency thereof. The views and opinions of authors expressed herein do not necessarily state or reflect those of the United States Government or any agency thereof. 
Energy and Transportation Science Division

\title{
MOISTURE DURABILITY ASSESSMENT OF SELECTED WELL-INSULATED WALL ASSEMBLIES
}

\author{
Simon Pallin, $\mathrm{PhD}$ \\ Philip Boudreaux \\ Manfred Kehrer \\ Diana E. Hun, PhD \\ Roderick K. Jackson, PhD \\ André O. Desjarlais
}

Date Published: December 2015

\author{
Prepared by \\ OAK RIDGE NATIONAL LABORATORY \\ Oak Ridge, TN 37831-6283 \\ managed by \\ UT-BATTELLE, LLC \\ for the \\ US DEPARTMENT OF ENERGY \\ under contract DE-AC05-00OR22725
}





\section{CONTENTS}

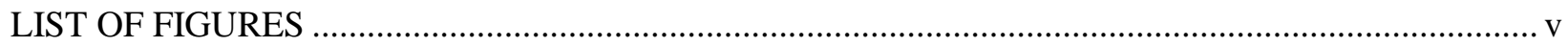

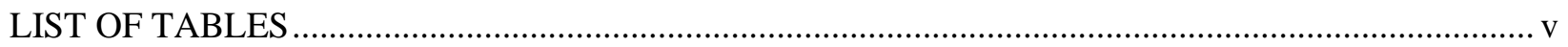

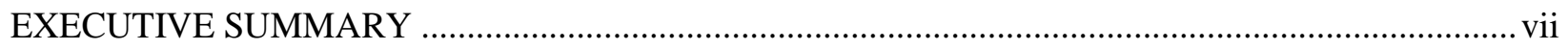

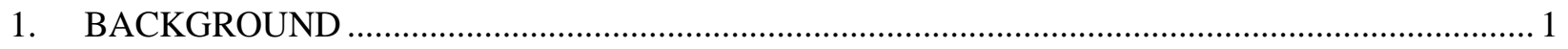

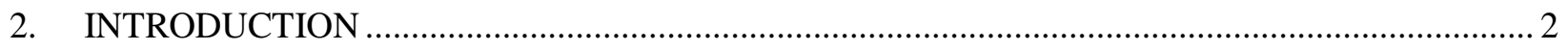

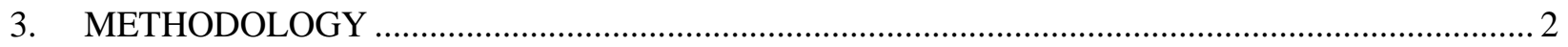

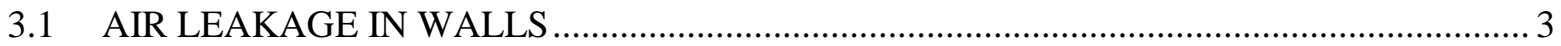

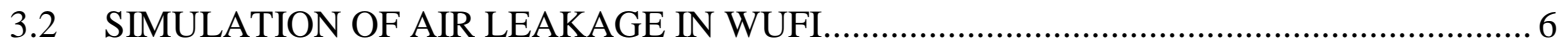

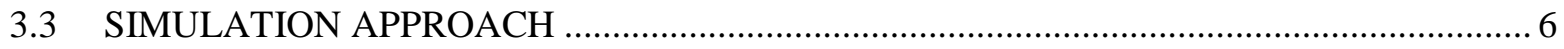

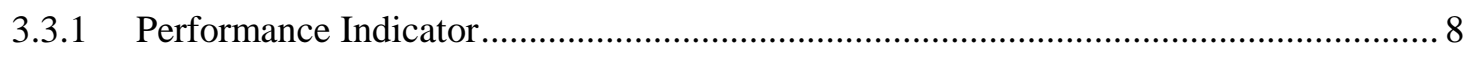

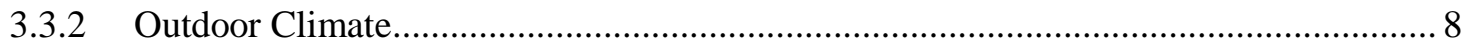

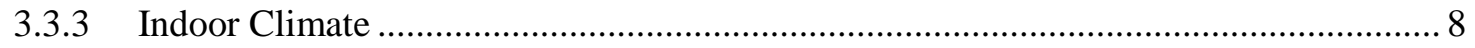

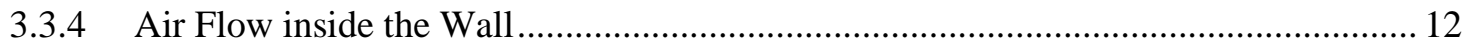

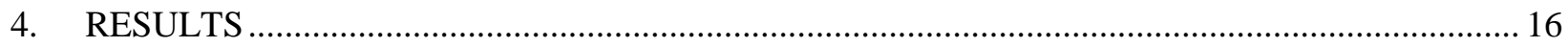

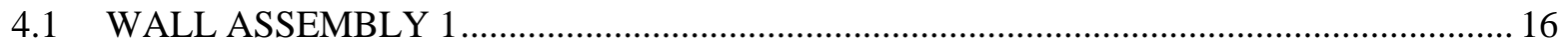

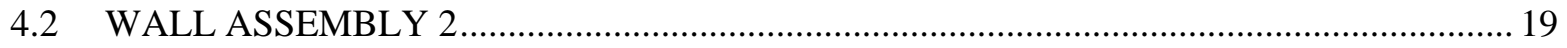

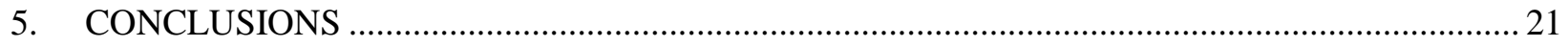

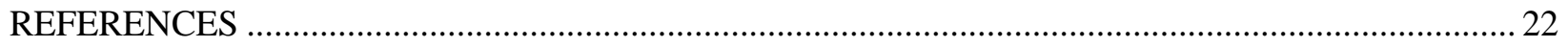

APPENDIX A

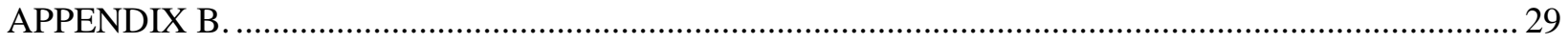





\section{LIST OF FIGURES}

Figure 1. Response to air leakage at steady state conditions for temperature and water vapor pressure at four locations inside an arbitrary air leakage path. ...................................................

Figure 2. Steady state conditions for relative humidity at four locations inside an arbitrary air

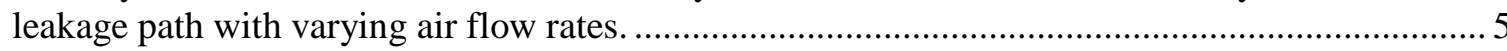

Figure 3. A comparison between WUFI 2D and WUFI 1D reveals that the $1 \mathrm{D}$ tool is capable of simulating air leakage at any location inside the air leakage path. ............................................ 6

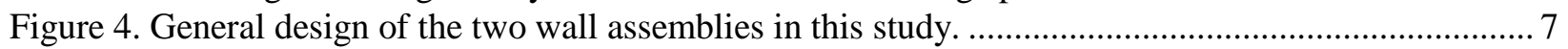

Figure 5. EnergyPlus simulation model house ............................................................................... 9

Figure 6. Probabilistic distribution of indoor moisture generation in homes as a function of household members.

Figure 7. Variation in air leakage area by converting ACH50 from the LBNL Residential

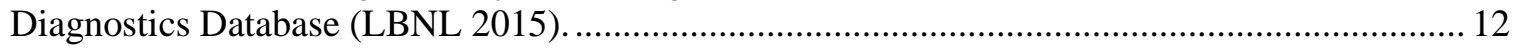

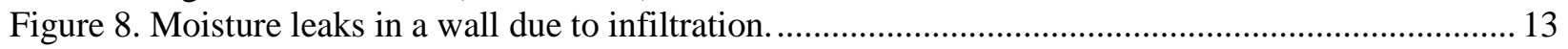

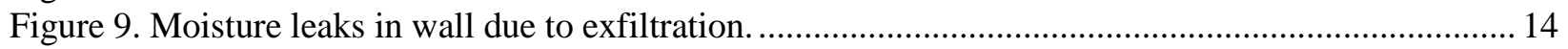

Figure 10. The larger chart depicts the fraction of air leakage in walls resulting in a potential

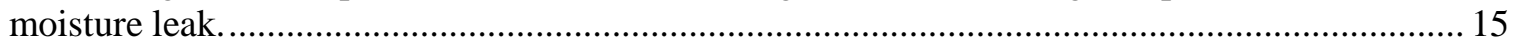

Figure 11. Design air leakage rates to evaluate hygrothermal performance of walls due to air leakage.

Figure 12. Hygrothermal performances for wall assembly 1, based on the mold growth index. Left, Houston; middle, New York; right, Minneapolis............................................................... 17

Figure 13. Correlation analysis for wall assembly 1 in the climate of Houston, TX................................ 18

Figure 14. Correlation analyses for wall assembly 1 in the climate of New York City and Minneapolis.

Figure 15. Hygrothermal performances for wall assembly 2, based on a mold growth indicator (MGI). Left, Chicago; middle, Anchorage; right, Minneapolis................................................ 20

Figure 16. Correlation analyses for wall assembly 2 in the climate of Chicago, Minneapolis, and Anchorage.

Figure 17. A comparison between 1D and 2D steady-state solutions for heat exchange in an air channel. 26

Figure 18. HAM penetration chambers at Oak Ridge National Laboratory. ........................................ 29

Figure 19. Wall specimen with thermocouples and relative humidity sensors located at multiple points. 29

Figure 20. Validation of the proposed $\eta$-method agrees well with measurements. 30

\section{LIST OF TABLES}

Table 1. Total R-value of the two wall designs used in this study .................................................... 7

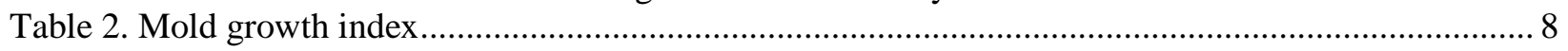

Table 3. Input values for EnergyPlus model to simulate indoor climate ........................................... 9 



\section{EXECUTIVE SUMMARY}

This report presents the results from studying the hygrothermal performance of two well-insulated wall assemblies, both complying with and exceeding international building codes (IECC 2015 2014, IRC 2015). The hygrothermal performance of walls is affected by a large number of influential parameters (e.g., outdoor and indoor climates, workmanship, material properties). This study was based on a probabilistic risk assessment in which a number of these influential parameters were simulated with their natural variability. The purpose of this approach was to generate simulation results based on laboratory chamber measurements that represent a variety of performances and thus better mimic realistic conditions.

In total, laboratory measurements and 6,000 simulations were completed for five different US climate zones. A mold growth indicator (MGI) was used to estimate the risk of mold which potentially can cause moisture durability problems in the selected wall assemblies. Analyzing the possible impact on the indoor climate due to mold was not part of this study. The following conclusions can be reached from analyzing the simulation results.

- In a hot-humid climate, a higher R-value increases the importance of the airtightness because interior wall materials are at lower temperatures.

- In a cold climate, indoor humidity levels increase with increased airtightness.

- Air leakage must be considered in a hygrothermal risk assessment, since air efficiently brings moisture into buildings from either the interior or exterior environment.

- The sensitivity analysis of this study identifies mitigation strategies.

Again, it is important to remark that MGI is an indicator of mold, not an indicator of indoor air quality and that mold is the most conservative indicator for moisture durability issues. 


\section{BACKGROUND}

Wall and building construction is becoming more energy efficient in the United States as a result of improved building codes and standards. This development is demonstrated in the 2015 International Energy Conservation Code (IRC 2015) and Standard 90.1-2013 from the American Society of Heating, Refrigerating and Air-Conditioning Engineers (ANSI/ASHRAE 2013). Both the insulation levels and the airtightness of buildings have increased dramatically. However, an improved energy performance can impact the moisture durability of building components such as walls and roofs (RAP-RETRO 2011). The main reason that more energy-efficient walls influence moisture damage is that increasing the insulation level places part of the building assembly in a colder environment. This impacts the moisture durability because a lower temperature reduces the capacity of common building materials to resist moisture damage. In cold climates, the exterior areas of buildings become colder as a result of increased thermal resistance; in warm climates, the interior materials become colder. If materials that are sensitive to moisture are located in an environment that becomes colder because of a higher level of insulation, the risk of critical relative humidity levels being reached, or even condensation, may be significant.

An increased risk of vulnerability to moisture damage also results from making buildings more airtight and adding insulation materials with low water vapor permeance. As a result of these measures, the drying potentials of wall or roof assemblies become lower and the assemblies become more sensitive to rain intrusion, initial construction moisture, or leakage of humid air.

Walls can be evaluated by simulations, laboratory measurements, and field experience. There are advantages and disadvantages to all three evaluation methods, and so they can benefit one another if conducted under controlled and measured conditions. Simulations can be criticized for not generating true conditions, and laboratory studies may be questioned because they are conducted under unrealistic conditions. Field studies have the disadvantages that they represent only performance in the conditions under which materials are evaluated, and that the exact hygrothermal properties of the materials studied are not known. However, if simulations can be evaluated against laboratory and/or field measurements, there are advantages to assessing walls based on multiple simulation scenarios. This study uses such an approach by performing hygrothermal (heat and moisture) risk assessments on wall assemblies and further validating the proposed methodology against laboratory measurements. With this approach, laboratory tests and simulation results can be used to select energy-efficient wall assemblies that show a low probability of moisture durability problems. The end goal of this study is to quantify the moisture risks of selected wall assemblies whose moisture durability is questioned by the building industry. Doing so can increase the adoption rate of reliable building designs and help the construction industry minimize the risks of moisture durability problems.

There exist studies with similar objectives; however, these represent partial hygrothermal evaluations because they rely mostly on field tests (Fox 2014, HIRL 2014) or laboratory studies (Desmarais, Derome et al. 2000, Langmans, Klein et al. 2012). Attempts have also been made to perform assessments based on simulations (Ojanen, Kohonen et al. 1994, Straube and Smegal 2012, Glass 2013), although, in these evaluations, field and laboratory tests have been limited to specific interior and exterior conditions. In addition, the moisture impact from air leakage is rarely considered because it is complicated to predict. Nonetheless, researchers have raised concerns about the effects of airflow on the durability of building envelope assemblies (Ojanen, Kohonen et al. 1994, Desmarais, Derome et al. 2000, Künzel, Zirkelbach et al. 2011). This study presents a method of handling the problems that stem from including air leakage in simulations of building components and subsequently presents risk assessments that account for influential parameters that will affect the hygrothermal performance of walls, including air leakage. 


\section{INTRODUCTION}

The hygrothermal performance of a wall assembly is affected by a large number of factors. Influential parameters include the outdoor and indoor environments, the material properties of the wall assembly, workmanship, and deviation from intended design, as well as human behavior inside buildings. The list of influential parameters is extensive, and taking all of them into account in performing risk assessments would be tedious if not impossible. Fortunately, most of the parameters having the largest impact on hygrothermal performance can be used in risk assessments.

Weather is straightforward to measure and can easily be incorporated into simulation models. Indoor humidity is harder to estimate, since it depends on both outdoor conditions and activities taking place inside homes that generate moisture. In addition, humidity is affected by the amount of air that leaks between the interior and the exterior and how much the air-conditioning unit runs. It also is affected by the hygrothermal properties of all the materials inside the home and those that are part of the building itself. A large number of factors affect the temperature inside a home, such as the $R$-values of building components; internal heat gain; characteristics of the heating, ventilation, and air-conditioning (HVAC) system; and thermostat settings. Air leakage affects the indoor temperature as well as the humidity. In fact, air leakage can be divided into two different types of leakage for analyzing hygrothermal performance: energy leaks and moisture leaks (Künzel, Zirkelbach et al. 2011).

Air leakage can be characterized as either an energy leak or a moisture leak. An energy leak can be described as air efficiently traveling from either the interior or the exterior through building components without having a significant impact on the materials inside the building component through which it travels. Moisture leaks however, have a diffuse rather than a direct air leakage path. As a result, the air that travels through building components has a larger impact on the surrounding materials and thus on their hygrothermal condition. Since air moves because of air pressure gradients, the major air leakage paths are those of least resistance - energy leaks. Typically, moisture leaks are assumed to be only 10\% of the total air leakage in walls (Lstiburek 2006, Künzel 2012). However, as buildings become more airtight, it is likely that energy leaks are declining, whereas moisture leaks remain at the same level or are reduced to a lesser extent. This is a plausible assumption because moisture leaks are diffuse and thus harder to predict and prevent.

Since moisture leaks affect the hygrothermal performance of walls, it is essential that this phenomenon be included in risk assessments of wall assemblies. Unfortunately, a diffuse air leakage path, such as a moisture leak, complicates the simulation process. To address this, a methodology has been developed and is presented in this report which allows moisture leaks to be included in performance evaluations of wall assemblies in a time-efficient and trustworthy manner.

\section{METHODOLOGY}

The aim of this study was to perform a hygrothermal risk assessment on two well-insulated wall assembly designs. To complete the task, a collaboration between two different simulation tools was needed.

EnergyPlus helped to simulate the indoor climate, which was used as the interior boundary conditions for the second simulation tool, WUFI. The reason for this approach is that WUFI is not capable of creating an indoor climate that depends on the running cycle of the HVAC unit, nor the whole-house heat transfer mechanisms required to simulate an indoor climate. On the other hand, EnergyPlus does not have the features that WUFI has to simulate the moisture conditions of materials and investigate them in detail.

Despite the combination of these two simulation tools, the capability to estimate air leakage inside wall assemblies properly was not available. Fortunately, WUFI provides enough features to work around the 
problem. The following section provides a solution for estimating air leakage in walls by preprocessing the exterior and interior air pressure conditions, thus allowing a simplified solution for air flow to better represent true conditions.

\subsection{AIR LEAKAGE IN WALLS}

Predicting air leakage is complicated because leakage depends on a large number of variables. The physical geometry of a building element, such as a wall, will determine where and how air is moving inside the element. Any abnormalities in the shape and dimensions of building materials, or less-thanperfect interfaces between the materials, may create air leakage paths through which air can travel if a differential air pressure exists across the abnormality. Theoretically, air leakage can be simulated through computational fluid dynamics modeling; however, to predict air flow accurately, the complete geometry, including abnormalities and interfaces must be known. Naturally, these essential requirements complicate the simulation process and affect the accuracy of the result.

We can make assumptions in the application of building physics that allow us to ignore much of the geometrical information needed to predict air leakage. For that reason, we actually can predict the effect of air leakage in building elements using a 1-dimensional (1D) simulation model. To better understand the approach presented, a review of Figure 1 and Figure 2 is helpful. These figures illustrate how effective heat and moisture are transported and transferred between convective air and adjacent surface materials (in this example, wood and glass wool) inside an air leakage path. Figure 1 illustrates the temperature and vapor pressure conditions inside an air leakage path when air is introduced to the wall assembly from the interior. If air is traveling from the inside to the outside, as seen in Figure 1 and Figure 2, "1" represents the temperature and vapor pressure of the indoor air. The changes in temperature and water vapor conditions from introducing air leakage inside an air leakage path are given for four locations and at a potential condensation plane, i.e., where warm and humid air might condense. A blue dot represents a location close to where the air enters the air leakage path, and a purple dot represents a location close to where the air exits. The curves presented in Figure 1 and Figure 2 are based on steady-state conditions as a function of air flow rate (in $\mathrm{cfm}$ ) inside the air leakage path.

For any of the curves, independent of studying the temperature or vapor pressure conditions, a higher air flow rate results in conditions closer to those of the indoor air. Studying the temperature and vapor pressure charts in Figure 1 individually also reveals that this response rate is higher for a location closer to the air entry point at a given air flow, compared with a location further down the air leakage path. The reason for this pattern is that the incoming air continually exchanges heat and moisture with the wall assembly while it travels. Consequently, there is less heat and moisture exchange at locations farther from the air entry point. As seen in Figure 1 and Figure 2, for a given air flow, the steady state wall temperature varies along the height of the wall more substantially than does the vapor pressure. This is because heat propagates much more efficiently than moisture in common building materials. Because heat is exchanged more rapidly, higher flow rates are required before a significant increase in temperature occurs in the wall. Because of this phenomenon, it is relevant to study a parameter that is a function of both temperature and water vapor pressure: relative humidity. In Figure 2, the relative humidity is depicted for the same four locations given in Figure 1. Studying the shapes of the curves demonstrates the impact of the phenomenon described above. Since vapor pressure adapts relatively faster than temperature, the relative humidity will increase until the temperature catches up. As seen in Figure 1 and Figure 2, the relative humidity peaks coincide with the inflection points of the water vapor pressure curves. Based on this analysis, it is clear that there will exist a certain air flow rate, under steady state conditions, at which the relative humidity will be at its highest independent of the location inside the air leakage path. 

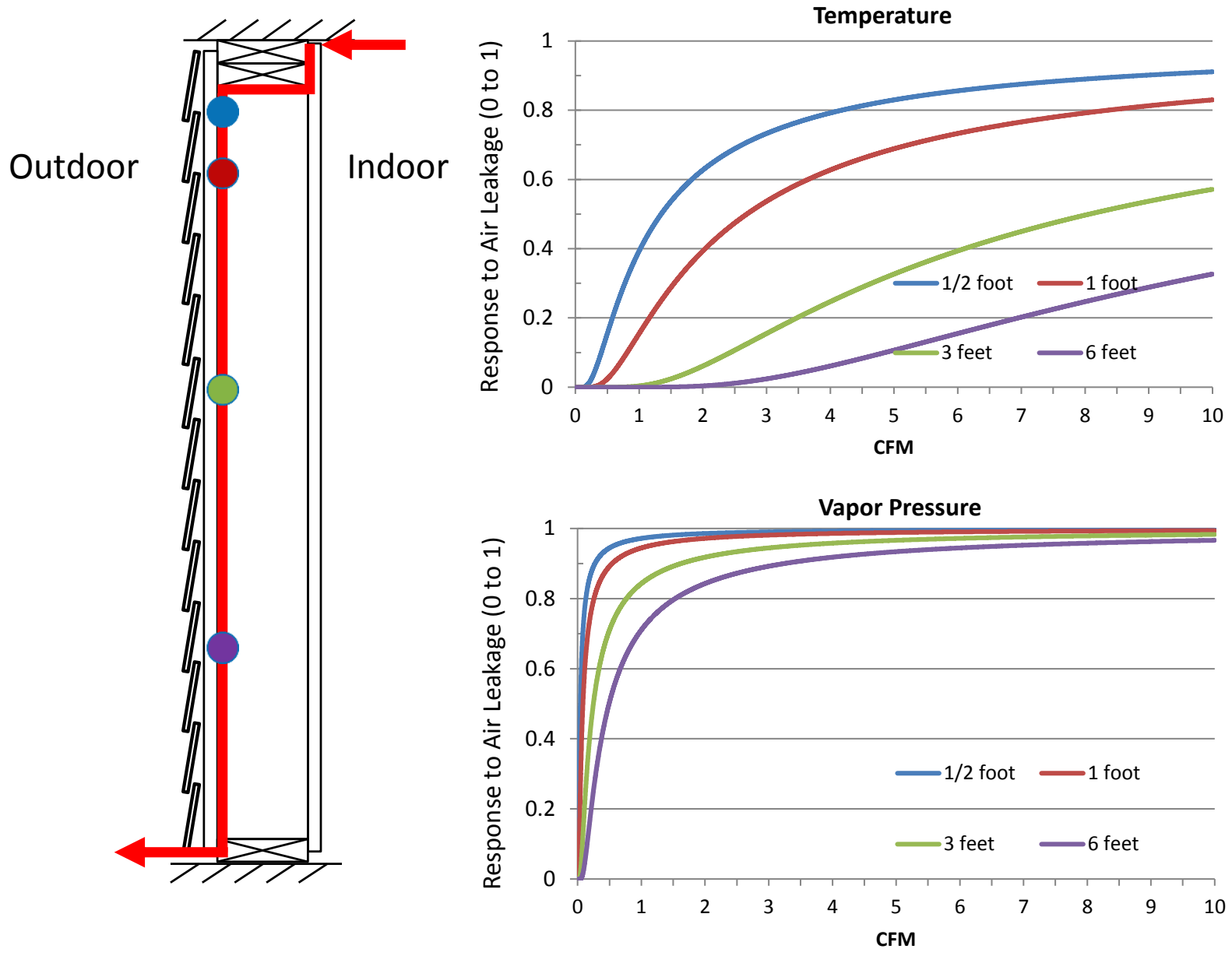

Figure 1. Response to air leakage at steady state conditions for temperature and water vapor pressure at four locations inside an arbitrary air leakage path. " 1 " means the conditions are exactly those of the interior, and " 0 " indicates the initial conditions when no air leakage is present.

A peak in relative humidity will occur for any of the depicted locations inside the air leakage path, and the air flow will determine where it occurs under steady state conditions. It is interesting that the peak value in relative humidity is independent of location, i.e., it can occur near the air entry point, in the middle, or where the air exits. However, a relatively high air flow rate is required to produce peaks in relative humidity at locations further into the air leak path, probably much higher than the flow rate typically seen inside walls, which is less than $1.0 \mathrm{cfm}$ (see Figure 11 in Section 3.3.4). Therefore, it can be assumed that locations near the air entry point are of most interest in evaluating the risk of moisture durability issues, since those locations are more prone to influence by air exfiltration. These findings justify why a hygrothermal assessment of risk due to air leakage in walls can be made close to where the air hits a potential condensation plane (blue marking in Figure 1 and Figure 2). Subsequently, a simulation tool that is capable of 1D transient heat, air, and moisture transfer, such as WUFI 1D, will suffice as long as the air leakage is handled properly. How air leakage should be handled in a hygrothermal calculation tool such as WUFI is presented in Section 3.2. 


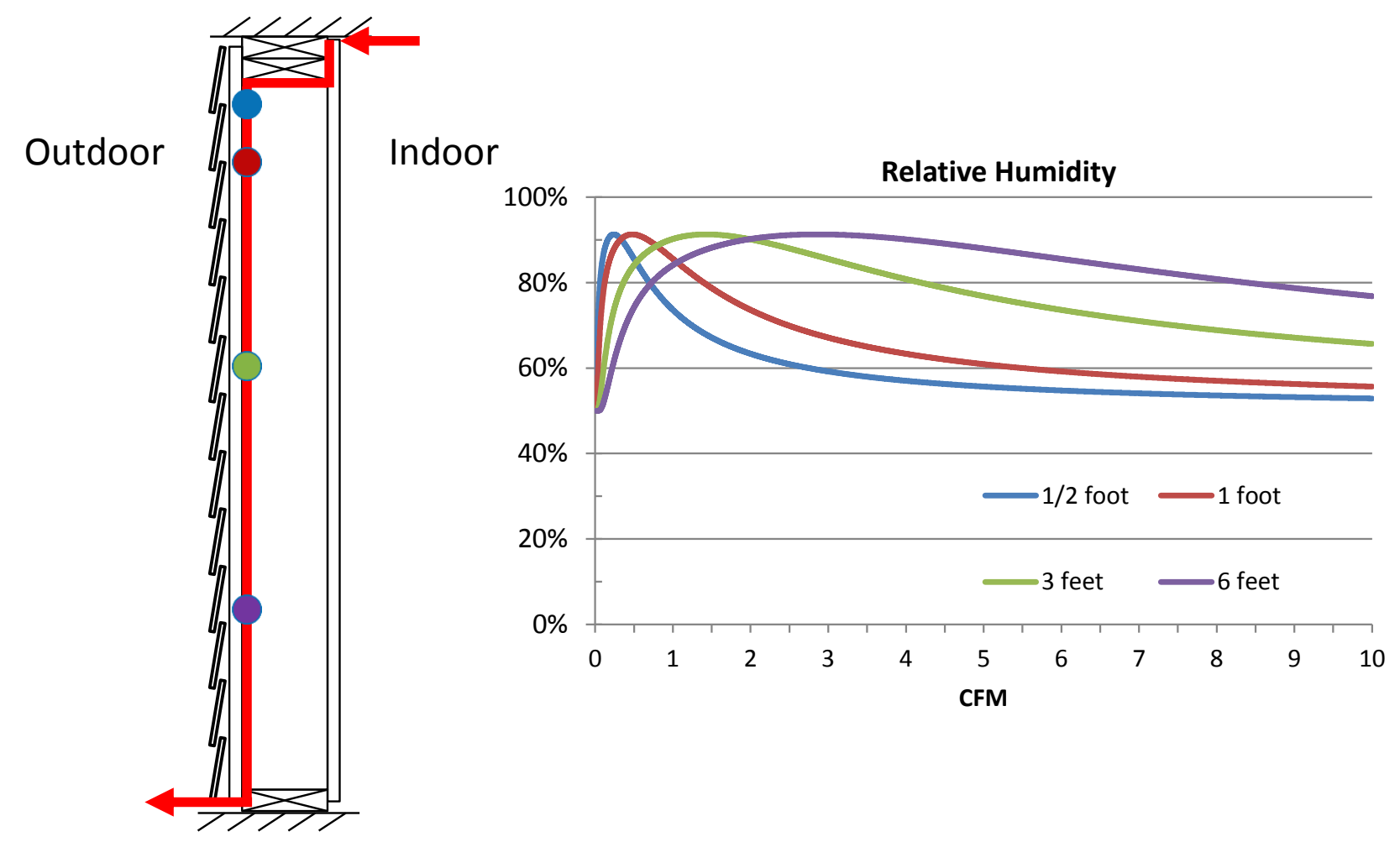

Figure 2. Steady state conditions for relative humidity at four locations inside an arbitrary air leakage path with varying air flow rates.

In addition, confirmation that a 1D calculation tool can replace a 2-dimensional (2D) tool was needed. Therefore, a 2D simulation model was created in WUFI 2D representing the air leakage path illustrated in Figure 3 and simulated with an arbitrary air exfiltration value. The wall was simulated for 1 year in the climate of Chicago, Illinois, and divided into 10 elements for which the hygrothermal conditions were recorded. These same elements were then created in 10 separate WUFI 1D models, in which the methodology to handle air leakage in 1D tools was applied (described in Appendix A). A comparison was then made with the simulation results from the 2D model and the 1D models. As seen Figure 3, WUFI 1D is a suitable tool to provide credible simulation results while optimizing the calculation time. 

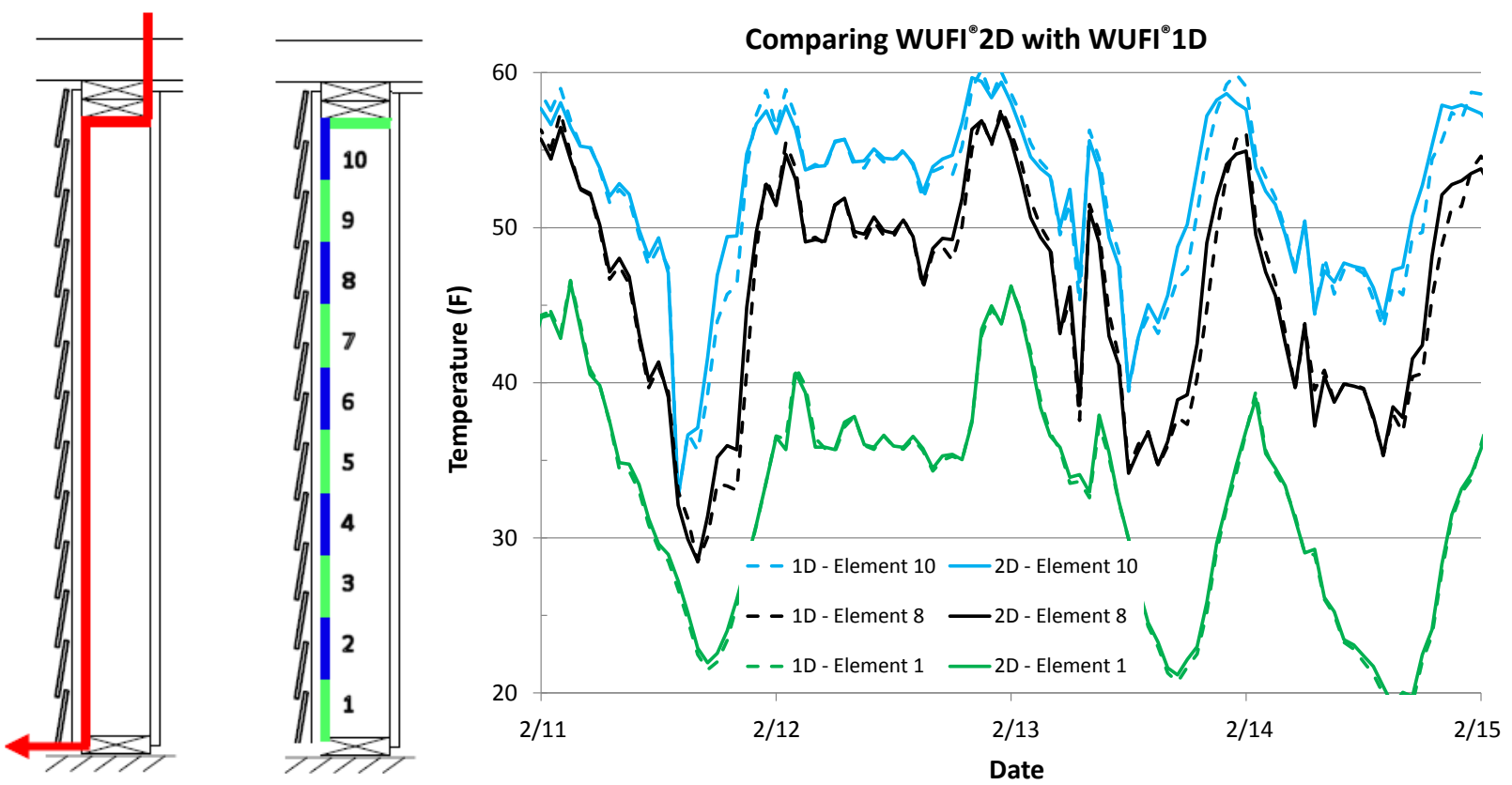

Figure 3. A comparison between WUFI 2D and WUFI 1D reveals that the 1D tool is capable of simulating air leakage at any location inside the air leakage path.

\subsection{SIMULATION OF AIR LEAKAGE IN WUFI}

The hygrothermal performance of a wall is highly influenced by air movement inside the wall. Unfortunately, these air movements are not easily evaluated and are time consuming and challenging to simulate in computer-based evaluation tools. The hygrothermal evaluation tool WUFI has an embedded feature to simulate air leakages, although its accuracy is questionable (Künzel, Zirkelbach et al. 2011). An approach has been presented (Pallin, Hun et al. 2014) that allows the embedded air leakage tool in WUFI to be used with higher accuracy. The approach is referred to as the $\eta$-method and basically converts the 1D-based WUFI feature to allow for two- or three-dimensional air leakage. A detailed description of the calculation steps behind the $\eta$-method is given in Appendix A. A minor improvement was made to the approach used to apply the $\eta$-method in previous years; therefore, further validation was needed. This validation proved the improvement to be a successful measure and is presented in Appendix B.

\subsection{SIMULATION APPROACH}

The walls selected in this study were based on input received from an advisory panel consisting of building science experts, and a survey of existing literature documenting a perceived risk of moisture related problems in higher performing wall assemblies. 
Two wall assemblies with somewhat similar designs were evaluated. As shown in Figure 4, the materials that they shared in common were:

- $\quad$ Vinyl siding

- Extruded polystyrene (XPS) as exterior insulation and air barrier (exterior insulation was used when required based on Climate Zone) or spun-bonded polyolefin as the air barrier when XPS was not present

- Oriented strand board

- $2 \times 6$ studs with R-19 fiberglass batt insulation

- Drywall

The first wall assembly in the present study was selected because questions have been raised about the IRC relaxing the use of a Class II interior vapor retarder based on increases in the amount of exterior continuous insulation or the presence of a vented cladding (HIRL 2013). The goal was to determine if the proposed moisture durability assessment supported these concerns.

Consequently, the first wall assembly used latex paint with 5 perms (Class III vapor retarder), unfaced fiberglass batts, and in some instances additional exterior insulation as shown in Table 1.

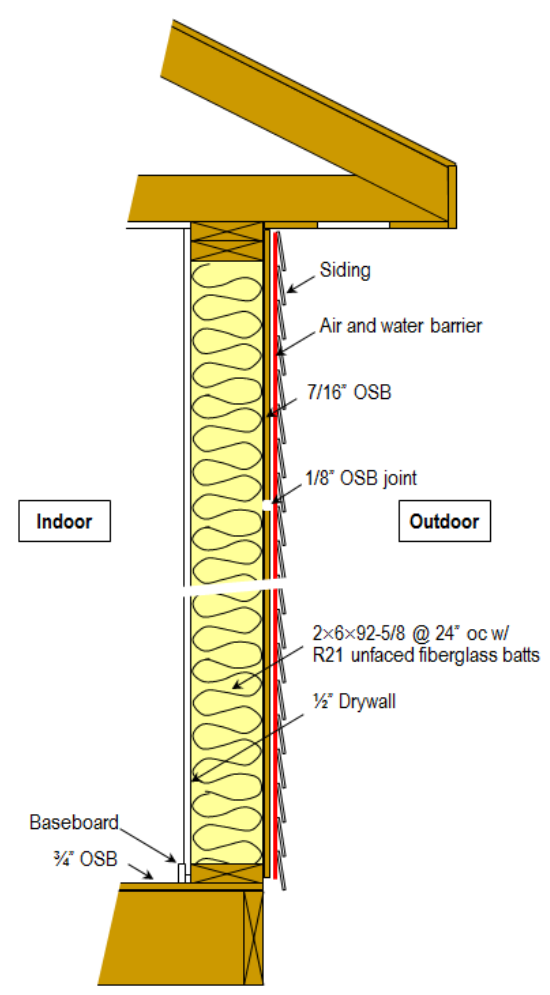

Figure 4. General design of the two wall assemblies in this study. A deviation from the 2015 IRC/IECC is that R20 insulation was utilized in the simulations for Houston, TX (Climate Zone 2), instead of R13 given that this study was meant to focus on well-insulated walls. Furthermore, note that the walls with extruded polystyrene (XPS) as exterior insulation also included oriented strand board (OSB), although using both materials in conjunction may be cost prohibitive in residential construction.

The second wall assembly had Kraft paper (1 perm) as a Class II interior vapor retarder. Insulation values comply with Table N1102.1.2 of the 2015 IRC as indicated in Table 1. Just as with the first wall assembly, OSB and XPS were used simultaneously.

Table 1. Total R-value of the two wall designs used in this study The second term, if any, refers to continuous insulation

\begin{tabular}{cccccc}
\hline $\begin{array}{c}\text { Wall } \\
\text { Assembly }\end{array}$ & $\begin{array}{c}\text { Houston, TX } \\
(\text { Climate Zone 2) }\end{array}$ & $\begin{array}{c}\text { New York, NY } \\
\text { (Climate Zone 4) }\end{array}$ & $\begin{array}{c}\text { Chicago, IL } \\
\text { (Climate Zone 5) }\end{array}$ & $\begin{array}{c}\text { Minneapolis, MN } \\
\text { (Climate Zone 6) }\end{array}$ & $\begin{array}{c}\text { Anchorage, AL } \\
\text { (Climate Zone 7) }\end{array}$ \\
\hline 1 & $\mathbf{2 0}$ & $\mathbf{2 0 + 3 . 7 5}$ & - & $\mathbf{2 0 + 1 1 . 2 5}$ & - \\
2 & - & - & $\mathbf{2 0}$ & $\mathbf{2 0}+\mathbf{5}$ & $\mathbf{2 0}+\mathbf{5}$ \\
\hline
\end{tabular}

The two walls were simulated using a full probabilistic approach, i.e., with stochastically varying input parameters. Naturally, not every input parameter was chosen to be varied, but rather a number of selected parameters proven to have the greatest impact on the hygrothermal performance (Pallin 2013). These parameters are outdoor climate, indoor heat and moisture generation, airtightness of the home (ACH50), airtightness of walls resulting in moisture leaks (see Section 1), and thermostat settings. 


\subsubsection{Performance Indicator}

In total, 1,000 simulation scenarios were completed for each wall assembly and climate zone. In each scenario, the parameters defined in the previous paragraph were varied based on their probabilistic distributions. For each wall assembly, three climate locations were used, giving a total of 6,000 simulated scenarios. The hygrothermal performance of these scenarios was evaluated using the Finnish mold growth model (Ojanen, Peuhkuri et al. 2011). In this model, the risk of mold growth is estimated using a mold growth index (MGI). This performance indicator has values from 0 to 6 , with each value corresponding to a level of mold growth according to Table 2 . The risk definition in the second column of Table 2 is a qualified assessment based on the MGI at interfaces and surfaces that are not in direct contact with the interior air (Viitanen, Krus et al. 2015). Although MGI is as indicator of mold, MGI does not specifically define the risk of neither affecting the moisture durability nor how it will potentially affect the indoor environment.

Table 2. Mold growth index (Hukka and Viitanen 1999, Ojanen, Peuhkuri et al. 2011, Viitanen, Krus et al. 2015)

\begin{tabular}{clc}
\hline Index & \multicolumn{1}{c}{ Description of growth rate } & Risk Level \\
\hline 0 & No growth & Low \\
1 & Small amounts of mold on surface (microscope), initial stages of local growth & Low \\
2 & Several local mold growth colonies on surface (microscope) & Low \\
3 & Visual findings of mold on surface, $<10 \%$ coverage or $<50 \%$ coverage of mold (microscope) & Moderate \\
4 & $\begin{array}{l}\text { Visual findings of mold on surface, 10-50\% coverage or }>50 \% \text { coverage of mold } \\
\text { (microscope) }\end{array}$ & High \\
5 & Plenty of growth on surface, $>50 \%$ coverage (visual) & High \\
6 & Heavy and tight growth, coverage approximately 100\% & High \\
\hline
\end{tabular}

In accordance with Table 2, the hygrothermal performance of the 6,000 completed simulation scenarios for two wall assemblies with varying indoor and outdoor conditions was evaluated as representing a low, moderate, or high risk of mold.

It is important to clarify that the risk of mold was evaluated at the most critical position inside the wall. Since a 1D simulation tool was applied, no other areas inside the wall assembly, other than the critical position, were evaluated by the MGI. Therefore, no analyses were done to estimate how widespread the mold growth would be.

\subsubsection{Outdoor Climate}

Five climate locations were used in this study; Houston, Texas (climate zone 2); New York, New York (climate zone 4); Chicago, Illinois (climate zone 5); Minneapolis, Minnesota (climate zone 6); and Anchorage, Alaska (climate zone 7). For each location, 5 years of consecutive weather data between 2010 and 2014 were implemented into the simulation procedure.

\subsubsection{Indoor Climate}

EnergyPlus was used to simulate the hourly temperature and humidity on the interior side of the wall. To accomplish this, a $2376 \mathrm{ft} 2$ home was modeled (see Figure 5) which represents an average home built 
between 1990 and 2009 according to Residential Energy Consumption Survey (RECS 2015). The indoor climate was based on six variables:

- Outdoor climate

- House characteristics (wall insulation, roof insulation, window characteristics, and foundation type)

- Thermostat settings

- Indoor moisture generation

- Indoor heat generation

- Airtightness of the house

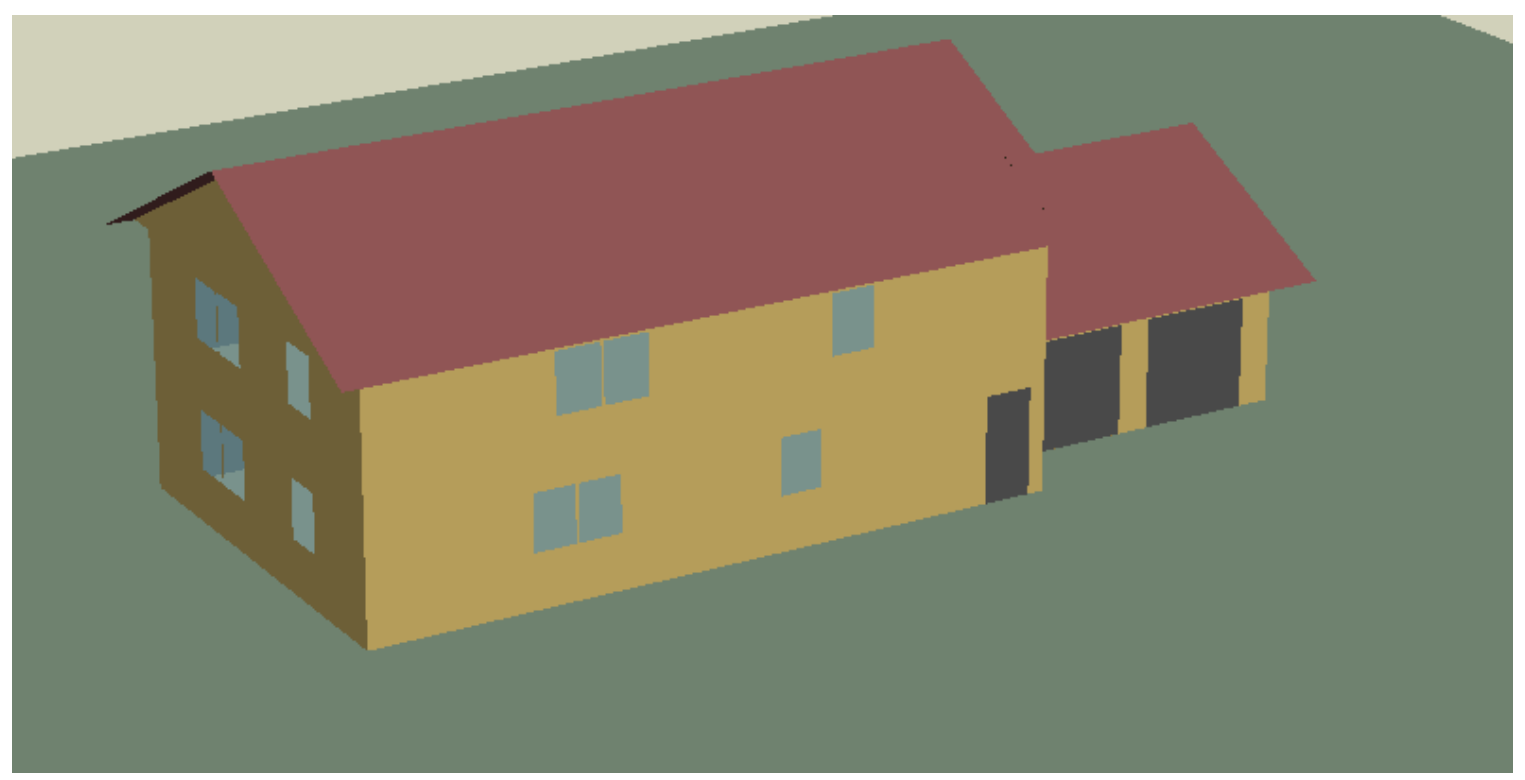

Figure 5. EnergyPlus simulation model house.

\subsubsection{House Characteristics}

The house characteristics depend on the climate zone in which the house is located. The characteristics used for this study are shown in Table 3. The wall, ceiling, and fenestration $R$-values and $U$-factors are based on the 2015 International Residential Code (IRC 2015). The foundation type is based on data from Oak Ridge National Laboratory (ORNL) and Residential Energy Consumption Survey.

Table 3. Input values for EnergyPlus model to simulate indoor climate

\begin{tabular}{cccccc}
\hline $\begin{array}{c}\text { Climate } \\
\text { zone }\end{array}$ & Wall R-value & $\begin{array}{c}\text { Ceiling } \\
\text { R-value }\end{array}$ & $\begin{array}{c}\text { Fenestration } \\
\text { U-Factor }\end{array}$ & $\begin{array}{c}\text { Glazed fenestration } \\
\text { solar heat gain } \\
\text { coefficient }\end{array}$ & Foundation \\
\hline $\mathbf{2}$ & & 38 & 0.4 & 0.25 & Slab \\
$\mathbf{4}$ & In accordance with & 49 & 0.35 & 0.4 & Crawlspace \\
$\mathbf{5}$ & design of wall & 49 & 0.32 & NR & Basement \\
$\mathbf{6}$ and 7 & assembly & 49 & 0.32 & NR & Basement \\
\hline
\end{tabular}




\subsubsection{Thermostat Set Points}

For this study, the National Renewable Energy Laboratory in Colorado provided data on indoor temperatures measured in houses in different climate zones (Booten and Norton 2014). The data included average and standard deviations in indoor temperature for cooling and heating seasons and in different climate zones. Based on these data and a survey of more than 50 homes in West Point, New York, a normal probability distribution was built and sampled to create 1,000 distinct thermostat set point pairs (heating and cooling) for each wall assembly and climate zone.

\subsubsection{Indoor Moisture Generation}

To estimate indoor humidity in houses, the amount of moisture generated inside houses is an essential piece of data. This information was provided by a newly developed simulation tool at ORNL referred to as the GIM-tool (generation of indoor moisture), which simulates residential generation of moisture by using statistical data for residential user behaviors together with moisture production rates from activities and appliances inside homes. It also uses the type of building and location to determine ranges in building size and outdoor climate conditions. The amount of moisture generated in homes is also climatedependent. The tool is a probabilistic instrument that simulates hourly variations of moisture generation in homes with a stochastic nature, as presented in Figure 6.

Moisture Generation Comparison for 1 to 4 Household Members

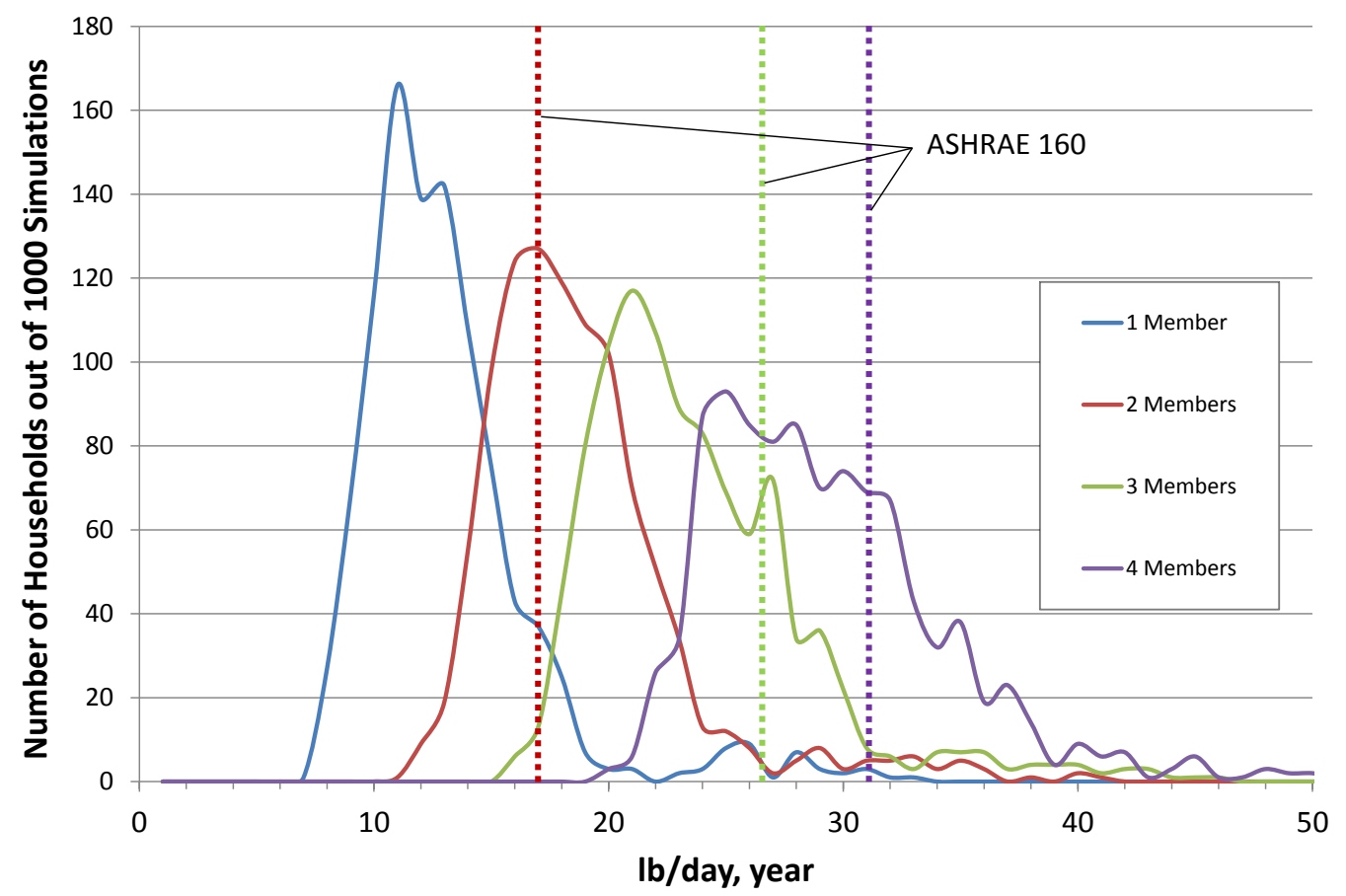

Figure 6. Probabilistic distribution of indoor moisture generation in homes as a function of household members. The probabilistic curves are depicted together with recommended generation rates (ASHRAE 1602011 ).

\subsubsection{Indoor Heat Generation}

The indoor sensible heat generation was based directly on the indoor latent heat (moisture) generation. To estimate the sensible heat generation the latent load was multiplied by 2.7. This is based on an 
estimation of the latent/sensible total load split from the appliances, miscellaneous electric loads and occupants from the Building America research benchmark.(Hendron and Engebrecht 2010)

\subsubsection{Airtightness of the Houses}

To determine the air change rate, the Lawrence Berkeley National Laboratory (LBNL) Residential Diagnostics Database was used (LBNL 2015), which contains whole-house air leakage data from about 147,000 homes. These data can be filtered by climate zone and house characteristics to yield a probability and cumulative distribution function for a particular home type in a particular climate zone. Based on these probability curves, the effective leakage area for 1,000 homes was computed and put into EnergyPlus for each simulated climate zone.

For the LBNL online Envelope Leakage Calculator the following inputs were used:

- Floor area: $2,376 \mathrm{ft}^{2}$

- Ceiling height: $8+8 \mathrm{ft}$ (2 floors)

- Year built: after 2000

- Weatherization Assistance Program? no

- ENERGY STAR certified? yes

- Region: depends on climate zone

- Foundation type: depends on climate zone

- Duct system location: inside the conditioned space

To determine the ACH50 for 1,000 different scenarios, a random number generator was used to sample the discrete cumulative distribution function (linear interpolation was used between the discrete points).

ACH50 was converted to an effective leakage area, which was used in EnergyPlus. An example of the resulting leakage areas for climate zone 4 is shown in Figure 7. 


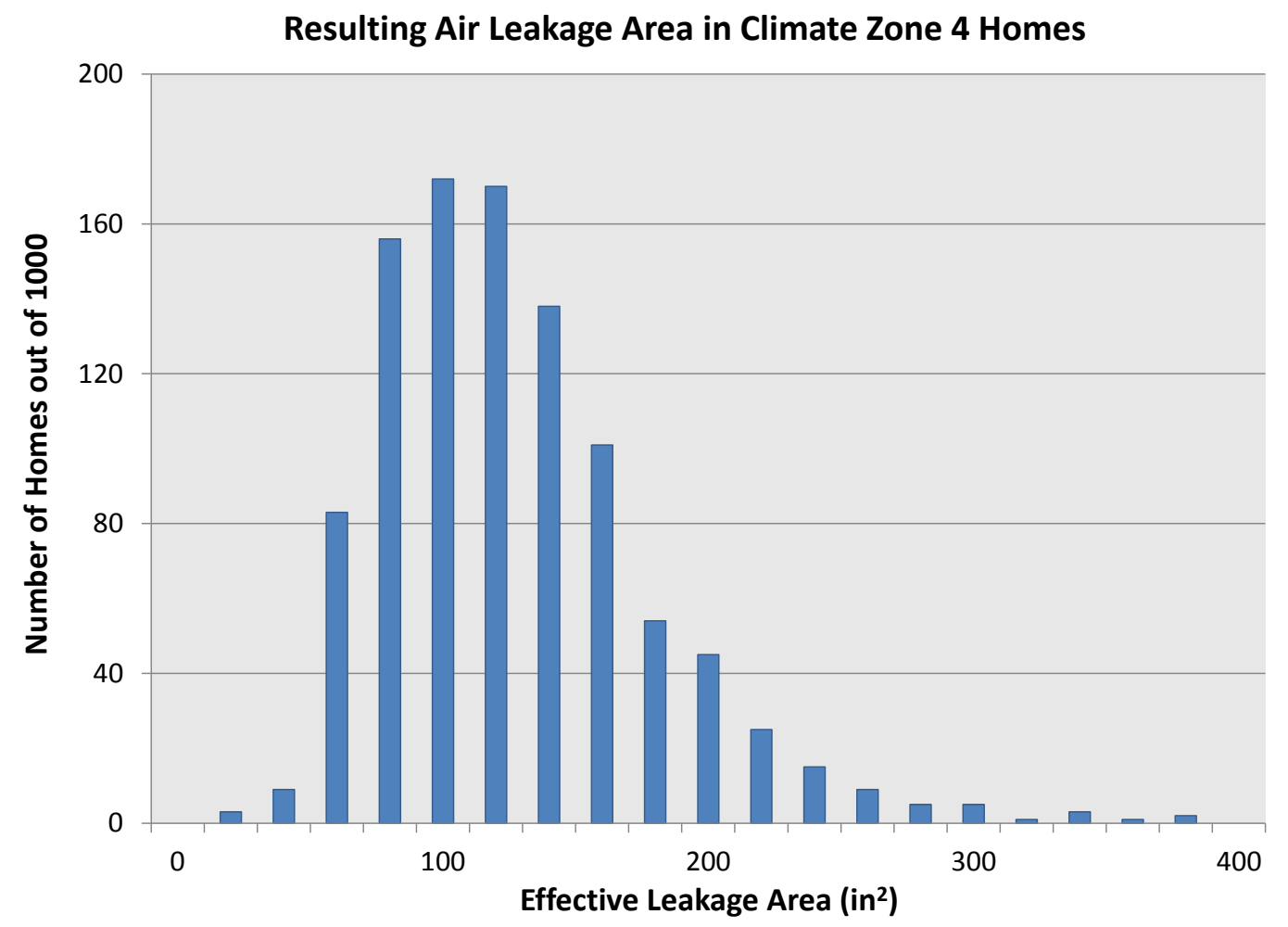

Figure 7. Variation in air leakage area by converting ACH50 from the LBNL Residential Diagnostics Database (LBNL 2015).

\subsubsection{Air Flow inside the Wall}

As was discussed in Section 1, air leakage in buildings can be categorized as either energy leaks or moisture leaks. Work was done in collaboration with this study to provide information on how much moisture leaks contribute to air leakage in walls (Hun and Atchley 2015). Using the Heat, Air and Moisture penetration chambers, as presented in Section Appendix B, several wall specimens were constructed to study where and how moisture leaks travel inside a wall construction. The design of the specimens complies with what was presented in Section 3.3. Several infiltration and exfiltration paths were studied, as illustrated in Figure 8 and Figure 9. These air leakage path all had one thing in common - they might result in an increase in the vapor content of the materials surrounding the air leakage path on which air travels; in that case, the leakage would be defined as moisture leaks.

For exfiltration or infiltration to become a moisture leak, the water vapor content of the environment from which the air travels needs to be higher than that of the materials inside the air leakage path. Whether exfiltration and infiltration were considered as a moisture leak will depend on outdoor climate conditions. In a hot and humid climate, the infiltration of outdoor air poses a higher risk if air travels toward a colder interior environment, as seen in Figure 8. In a colder outdoor environment, the risk is higher if warm and humid air exfiltrates from the inside toward a colder surface farther out in the wall. Therefore, the wall assemblies that were simulated in climate zones 2 and 4 were evaluated for air infiltration, whereas walls in climate zones 4 through 7 were simulated for exfiltration. The overlap is intentional because climate zone 4 is a mixed climate. 


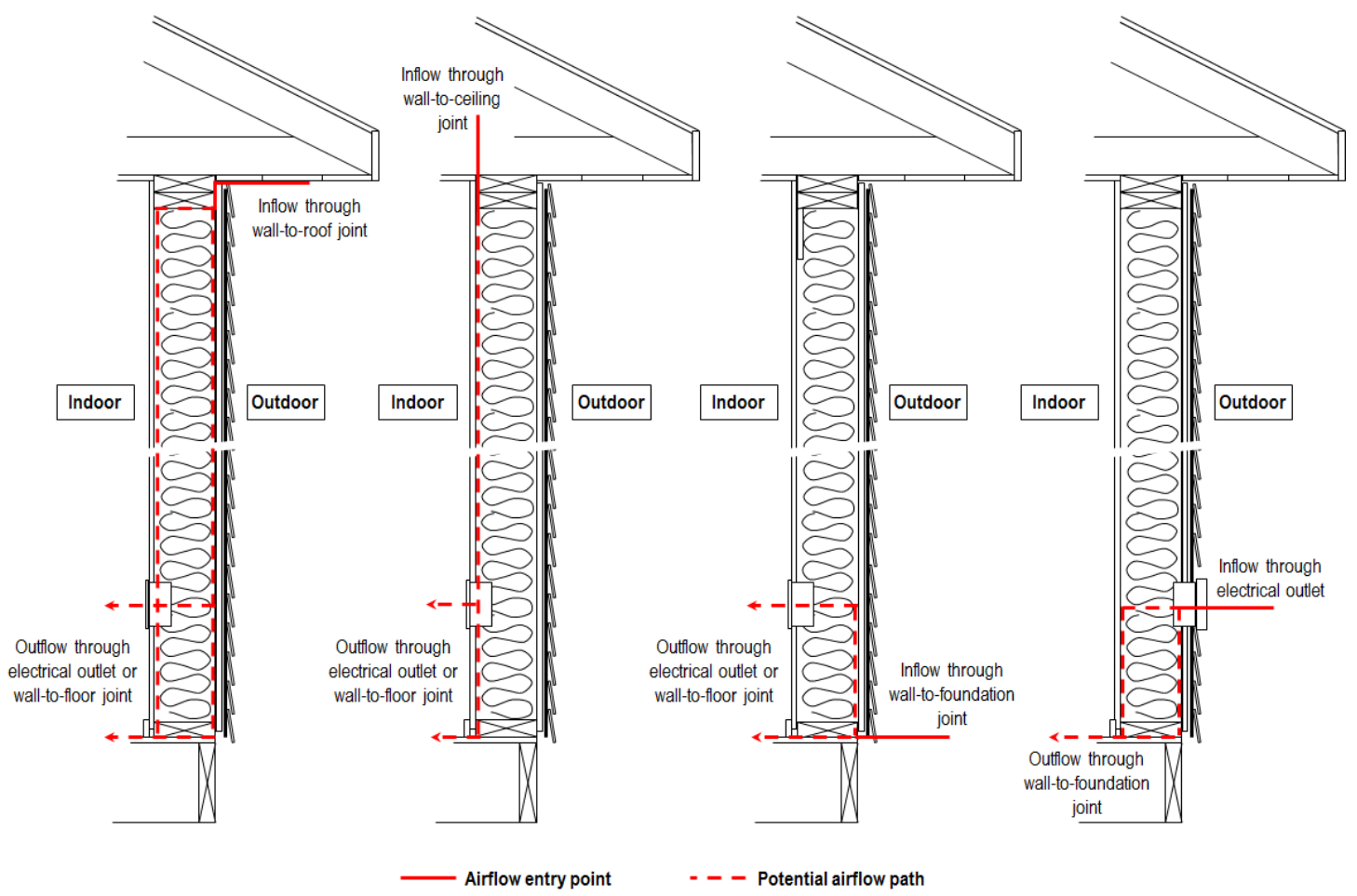

Figure 8. Moisture leaks in a wall due to infiltration.

As seen in Figure 8 and Figure 9, air may travel through joints, such as wall-to-roof, wall-to-ceiling, and wall-to-foundation joints. Air may also travel through penetrations, such as electrical outlets. By isolating these potential leakage spots, the air permeability, (i.e., the air resistance to moisture leaks) can be measured. The upper left-hand chart of Figure 10 presents the range in airtightness $\left(\mathrm{cfm} 50 / \mathrm{ft}^{2}\right)$ due to moisture leaks, based on measurements taken in the heat, air, and moisture penetration chambers at ORNL. The data collected from measuring these potential moisture leaks are presented as a cumulative distribution function and range from 0.01 to $0.17 \mathrm{cfm} 50 / \mathrm{ft}^{2}$. Since moisture leakage was one of the varying parameters for this study, this probabilistic distribution was used to determine the air flow through the two wall assemblies that may result in moisture durability issues.

(For further reading on how the study was conducted, a full description of the work is presented in the report Air Leakage Rates in Typical Air Barrier Assemblies (Hun and Atchley 2015).

A comparison between moisture leaks and energy leaks was made by comparing the overall airtightness of walls in constructed homes (with identical designs) with the airtightness of moisture leaks. In 12 homes at West Point, New York, the airtightness of walls was measured using a guarded blower door technique. This technique allows isolation of the air leakage through the walls from the leakage through the rest of the building. The results from measuring the airtightness in these homes are presented in the upper righthand chart of Figure 10. By comparing the extent of moisture leaks with the overall wall airtightness, a relationship between the two can be established. The bottom chart of Figure 10 reveals that about $10 \%$ of the air leakage in walls consists of moisture leaks. These findings are in agreement with previous studies (Lstiburek 2006, Künzel 2012). 


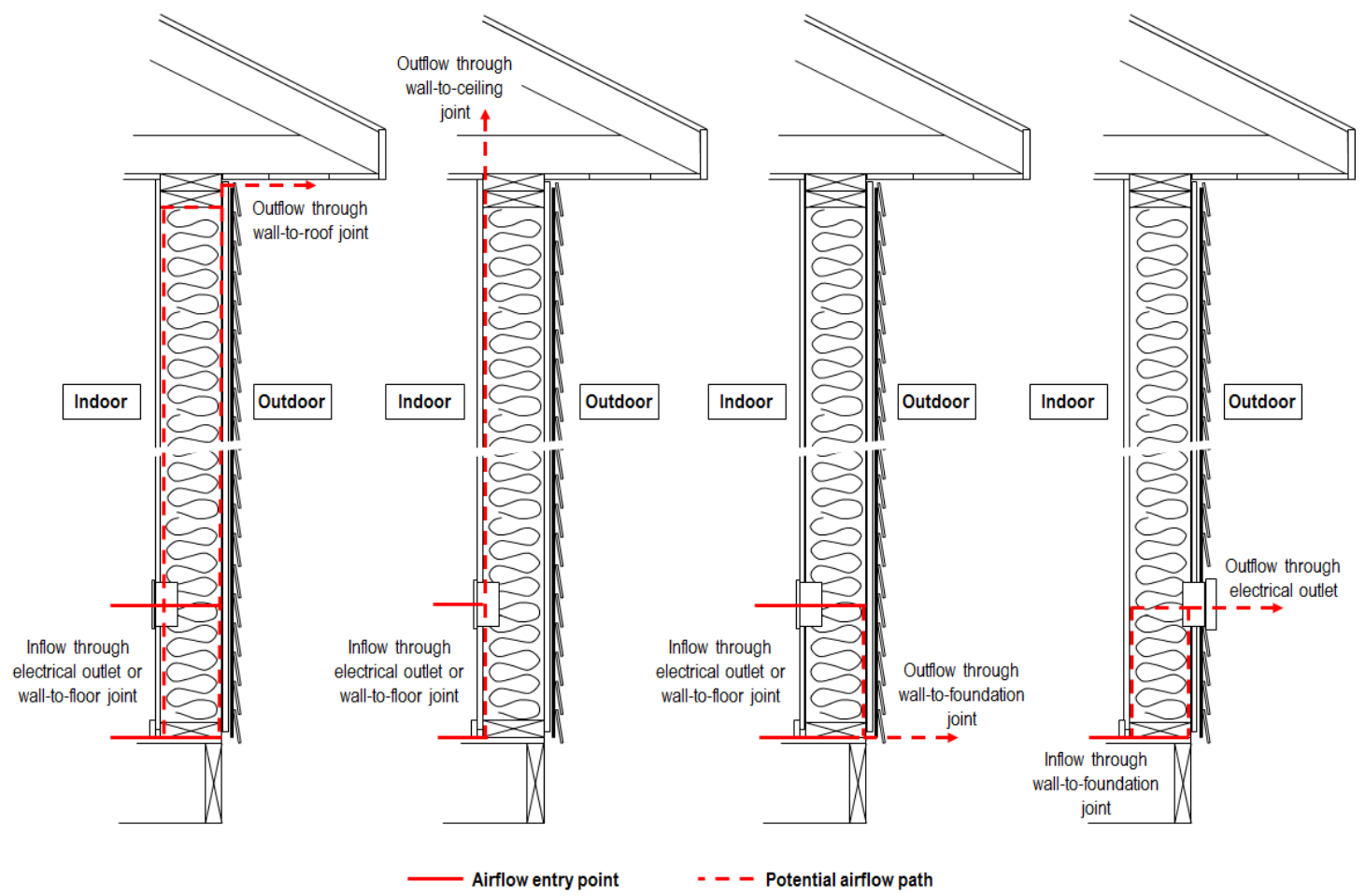

Figure 9. Moisture leaks in wall due to exfiltration.

Information regarding the air permeability of moisture leaks is essential to estimate how far the air travels and how it will impact the hygrothermal performance of walls. However, it is also essential to determine the air pressure differential between the interior and exterior surface boundaries. There are three primary factors that impact the air pressure gradient: wind forces, temperature gradient between the interior and exterior, and the HVAC system balance. For this study, the first two factors were considered, whereas any discrepancies in return and supply air pressure differences were assumed to be leveled out when considering the overall building enclosure.

Data for the wind speed, together with data for wind direction, enable estimation of the relative pressure differences at the wall surface based on structural design standard (ASCE/SEI 7-10 2010). Together with weather data, they were used to determine the wind-induced pressure gradient on an hourly basis. The orientation of the wall was determined by analyzing which direction resulted in either the highest infiltration rate or exfiltration rate. In warmer climates, the orientation that resulted in highest infiltration rates was determined, whilst for cold climates, the most dominant orientation for exfiltration was found; one orientation for each climate location. 

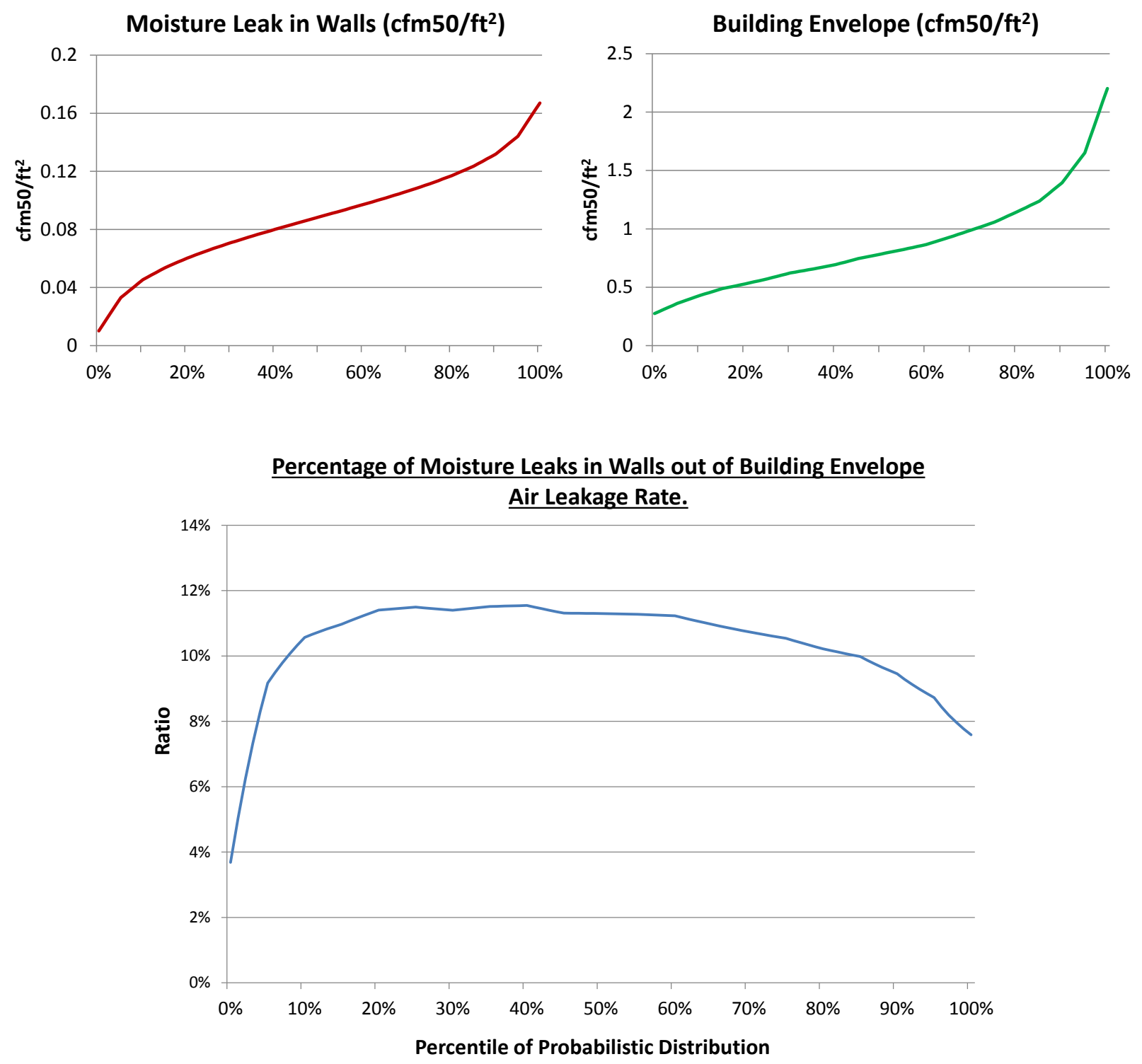

Figure 10. The larger chart depicts the fraction of air leakage in walls resulting in a potential moisture leak. The upper left chart presents the probability distribution of moisture leaks in walls, and the upper right represents a probabilistic distribution of the overall air leakage in walls; both are presented as an air leakage rate $\left(\mathrm{cfm} / \mathrm{ft}^{2}\right)$.

An example of how the perpendicular wind speed (normal to incident wall surface) affects the actual moisture leakage rate is illustrated in Figure 11. In this contour plot, the design air flow rate (in $\mathrm{cfm}$ ) is found by applying the approach presented in Section 3.1 (the most critical location for moisture durability) together with the airtightness of the building envelope and the wind speed. The relationship between the airtightness of the building envelope and the moisture leaks complies with the $10 \%$ ratio, as seen in Figure 10. The purpose of the plot in Figure 11 is to illustrate what actual design air flow rates should be applied in a simulation tool like WUFI to better predict the hygrothermal performance. 
Moisture Leak in a Wall depending on Perpendicular Wind Speed and

Air Tightness of Building Envelope (cfm)

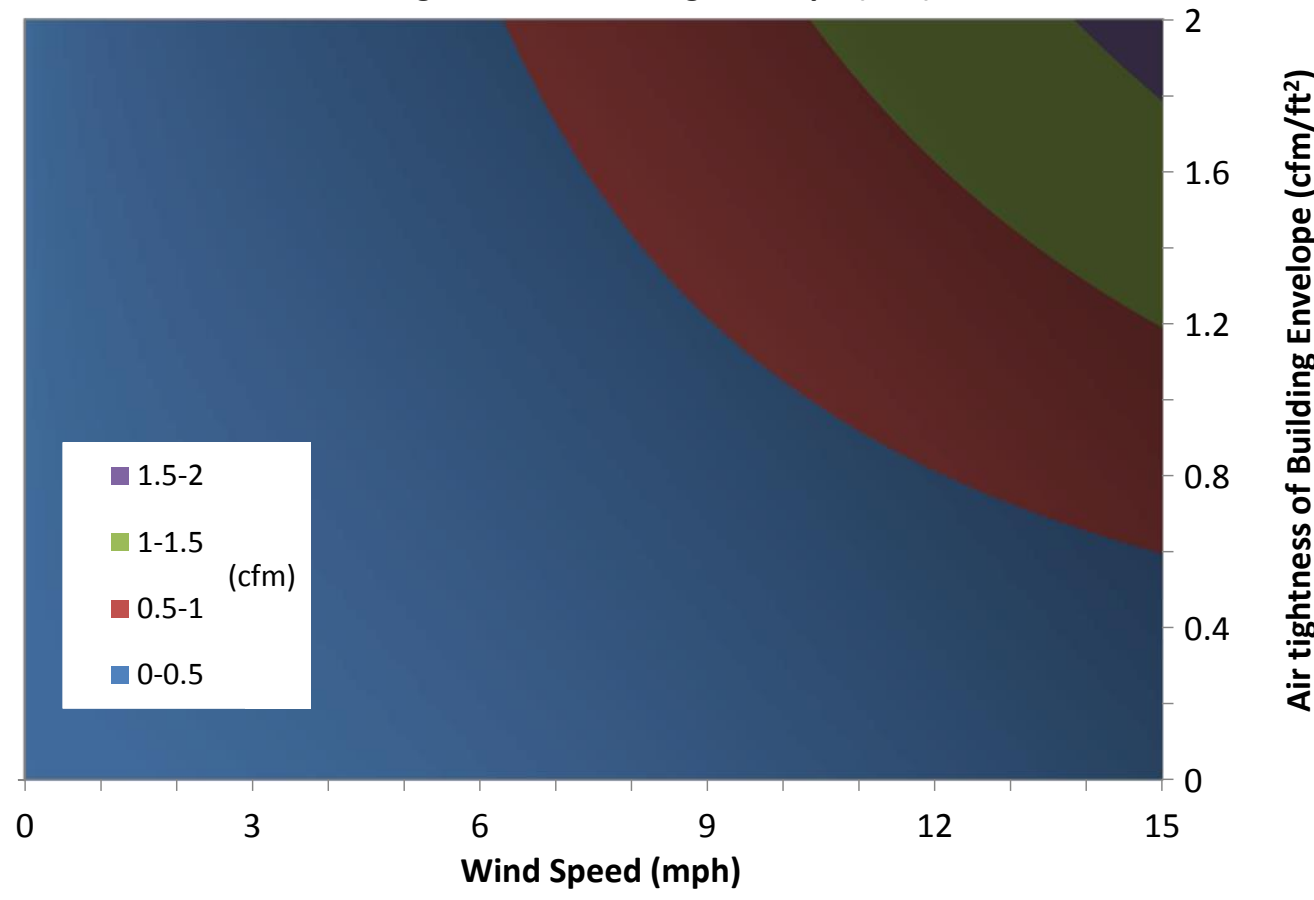

Figure 11. Design air leakage rates to evaluate hygrothermal performance of walls due to air leakage.

\section{RESULTS}

\subsection{WALL ASSEMBLY 1}

The results of the probabilistic risk assessment conducted for this study were evaluated using a performance indicator for mold (MGI), as described in Section 3.3 and Table 2.

For the first wall assembly (in compliance with ICC 2015, Section 702.7.1), the risks of mold growth were evaluated in climate zones 2, 4 and 6, and are presented in Figure 12. For climate zone 2, the wall was evaluated with an orientation that resulted in highest exterior air infiltration rates and in climate zone 6 for indoor air exfiltration. In climate zone 4, both infiltration and exfiltration were evaluated, thus resulting in two different wall orientations. As seen in this bar diagram, there could be a large mold risk associated with the studied wall assembly in climate zone 2 (left; Houston, Texas). According to the results, about $10 \%$ of the walls can be expected to have visual evidence of mold covering at least $10 \%$ of the surface area. For climate zone 4 (middle; New York) and climate zone 6 (right; Minneapolis), the risks of mold growth are substantially lower. The results from simulating the risk of mold growth in New York reveal that $1.6 \%$ of the walls have a high risk of visual mold, while in Minneapolis that risk is lower than $1 \%$.

The MGI for New York, presented in Figure 12, is the result of including the moisture leaks from exfiltration of indoor air. For the case of air infiltration, the risks were negligible. 


\section{Mold Growth Index at 3 Climate Locations - Wall Assembly \#1}

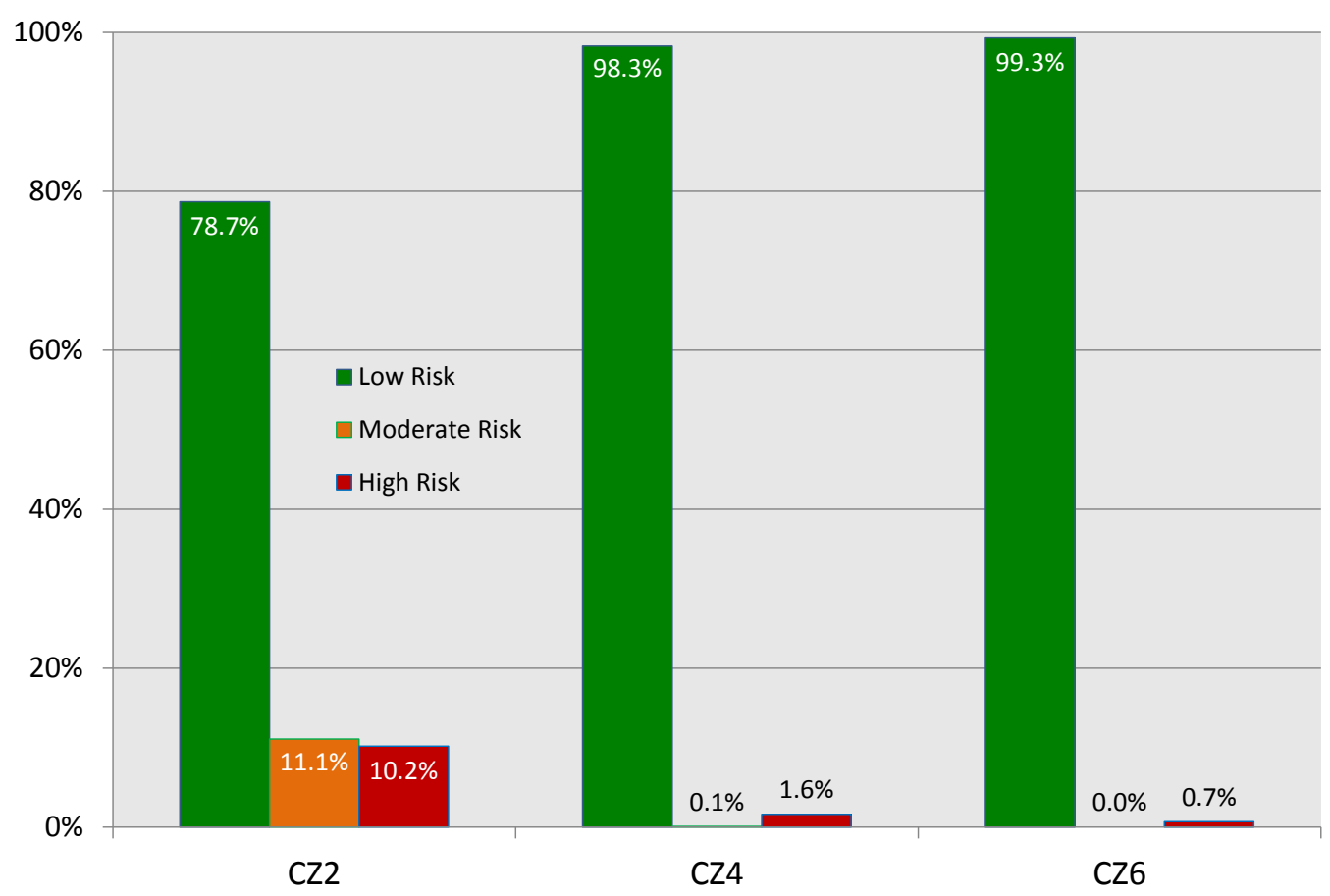

Figure 12. Hygrothermal performances for wall assembly 1, based on the mold growth index. Left, Houston; middle, New York; right, Minneapolis.

To understand the results in Figure 12, it is relevant to investigate how much each varying parameter in the simulations affects the risk of mold growth. Such a correlation analysis is presented in Figure 13 and Figure 14 Figure 13 shows results for the risk of mold growth resulting from infiltration of outdoor air, and Figure 14 presents the risk due to exfiltration of indoor air. The correlations between the varying parameters and the MGI are measured by a factor from -1 to 1 , where " 0 " means no correlation, " -1 " means a full negative correlation, and "1" means a full positive correlation. Based on the correlations in Figure 13, it is clear that one parameter has a very large impact: the cooling set point for the thermostat has a strong negative correlation with the risk of mold growth, meaning that the lower the temperature, the higher the risk. If the indoor temperature is lower, the temperature of the material inside the wall is also lower, thus increasing the risk of condensation or high levels of relative humidity. As expected, indoor moisture generation does not impact the risk of mold growth, because it is the risk due to outdoor air infiltration that is being evaluated. The wall permeability correlates with the MGI; the correlation is not very strong but is still recognizable. The rightmost column in the chart is a parameter created by considering the ratio between indoor moisture generation and wall permeability. The reason that air permeability has a positive correlation, while the ratio has a negative correlation, is that wall air permeability is applied as the denominator. This ratio is not relevant in studying infiltration, but it is very important in the analyses to follow.

Before analyzing the correlations between the MGI and the varying parameters for climate zones 4 and 6 , it is important to emphasize that any correlation is weaker if the performance indicator, such as the MGI, has no significant value i.e. the risks are low. Nevertheless, the analyses from the two climate zones have in common that both indoor moisture generation and air permeability have an impact. It is interesting that, in contrast to the results for a wall in a hot climate, a higher airtightness of the wall increases the risk in zones 4 and 6 . Although it has less impact than air permeability, indoor moisture production also 
increases the mold risk. The relationship between high indoor moisture generation and low air permeability shows by far the strongest correlation.

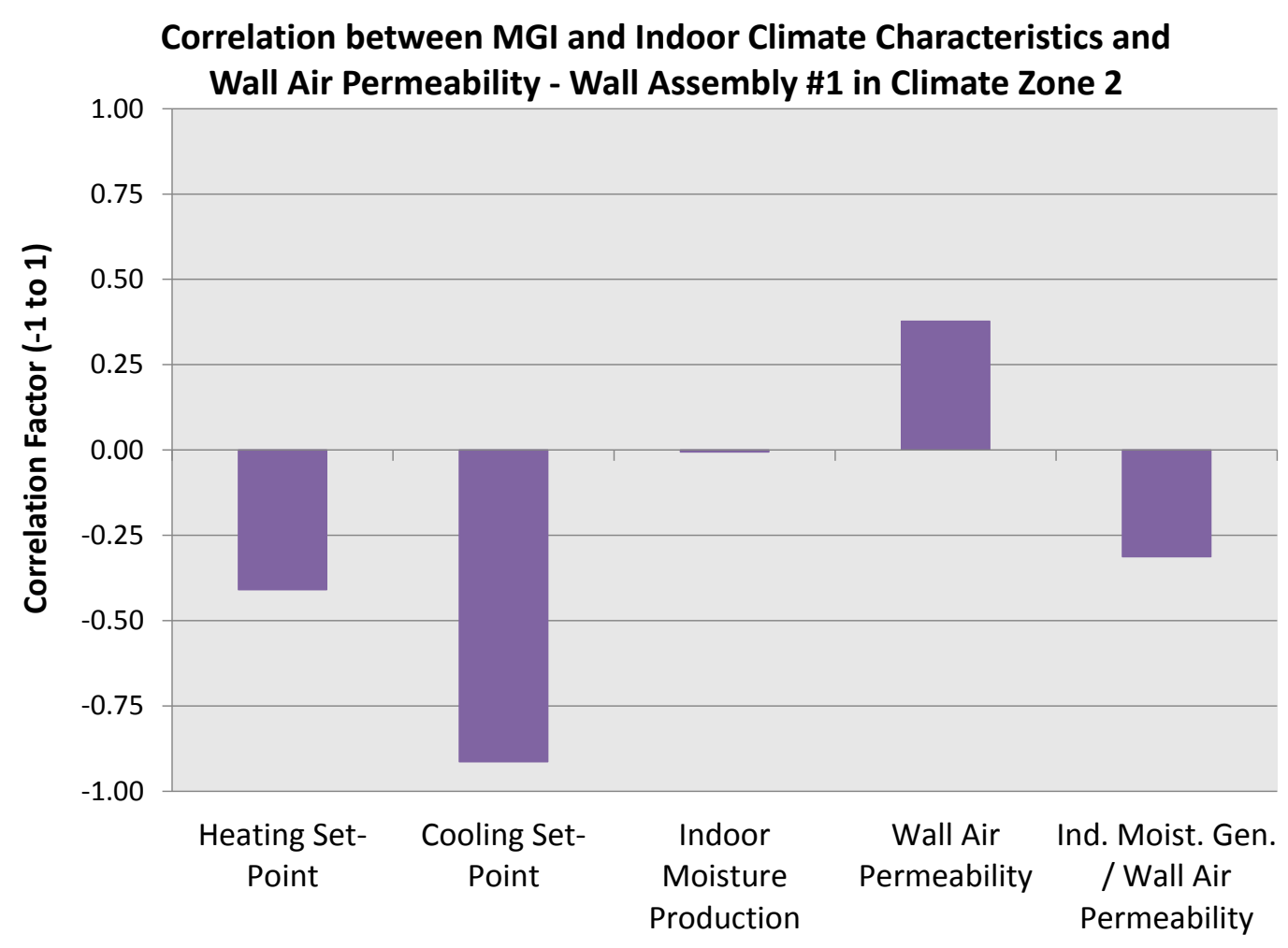

Figure 13. Correlation analysis for wall assembly 1 in the climate of Houston, TX. 


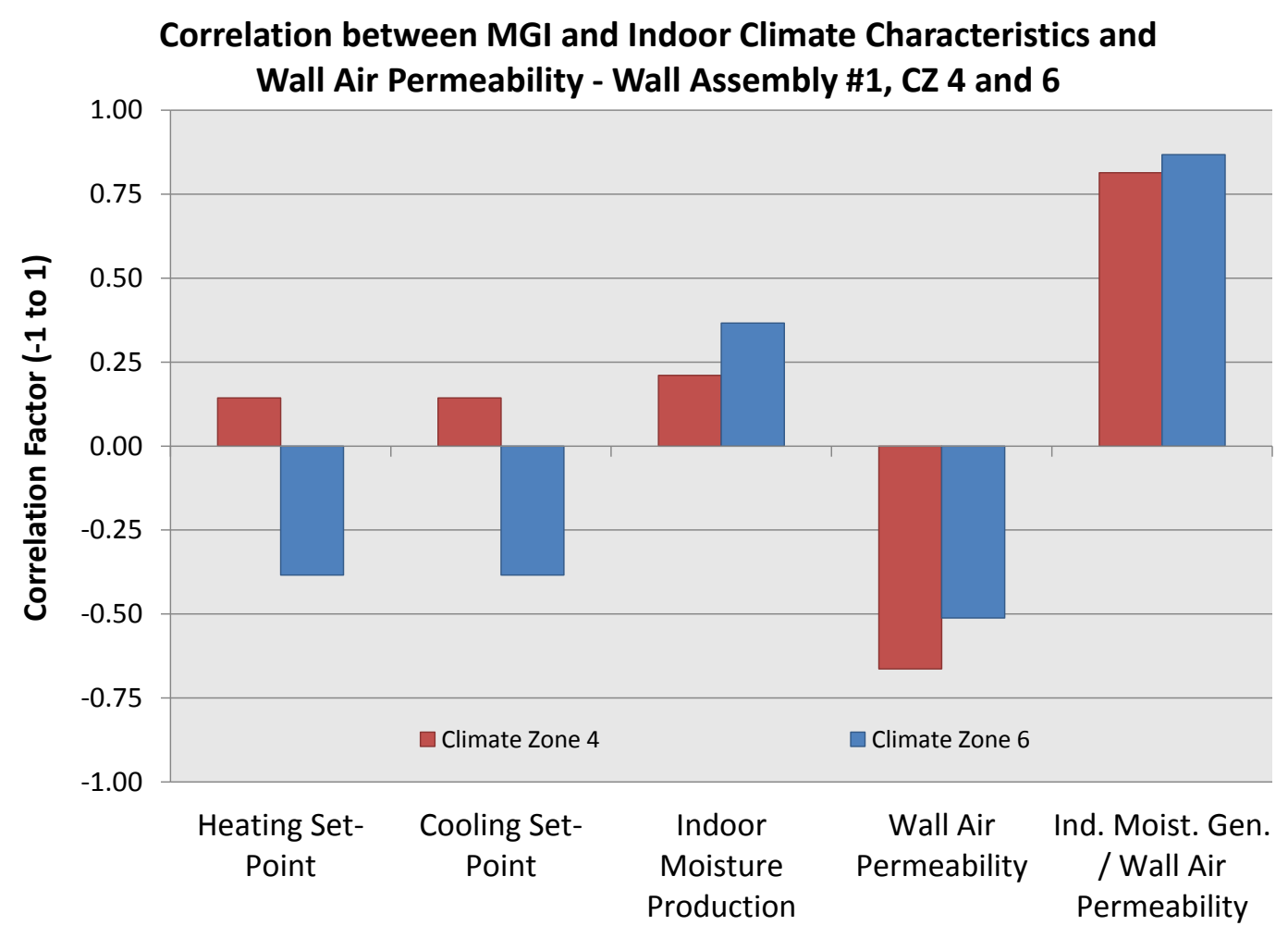

Figure 14. Correlation analyses for wall assembly 1 in the climate of New York City and Minneapolis.

\subsection{WALL ASSEMBLY 2}

For the second wall (in compliance with IECC 2015, R402.1.2), the risks of mold growth were evaluated in climate zones 5, 6, and 7. As seen in Figure 15, the risk of visual mold coverage of at least $10 \%$ is significant for the walls in climate zones 5 (Chicago) and 7 (Anchorage, Alaska). In climate zone 6 (Minneapolis), the risk is lower. All three walls were evaluated due to indoor air exfiltration.

The correlation factors for the three climate zones show very good agreement. Figure 16 indicates clearly that indoor moisture production will have an impact on wall performance, slightly more than does air permeability. The strongest correlation is seen for high indoor moisture production together with low wall air permeability (high airtightness). On average, the correlation is as strong as 0.9 . 


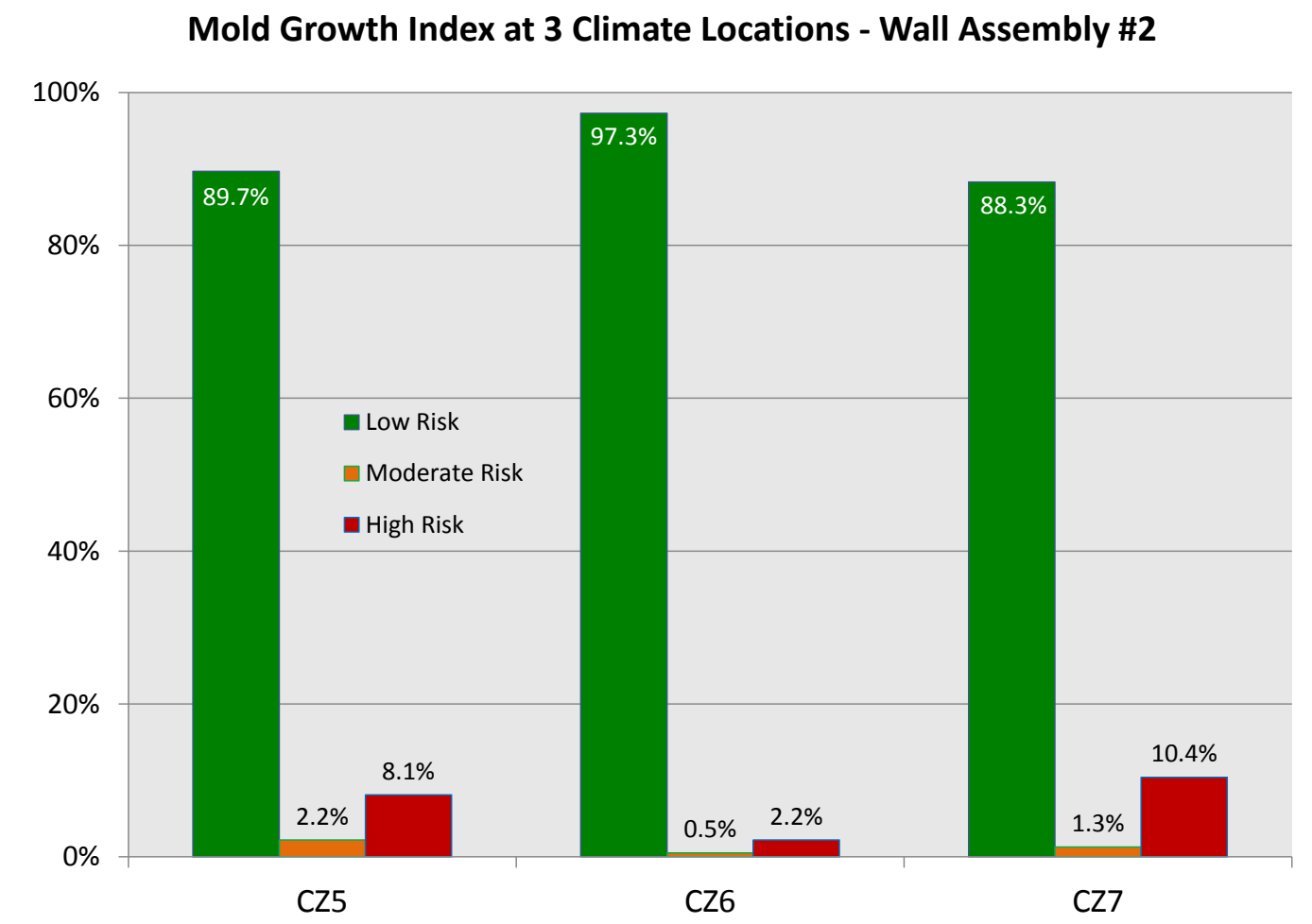

Figure 15. Hygrothermal performances for wall assembly 2, based on a mold growth indicator (MGI). Left, Chicago; middle, Anchorage; right, Minneapolis.

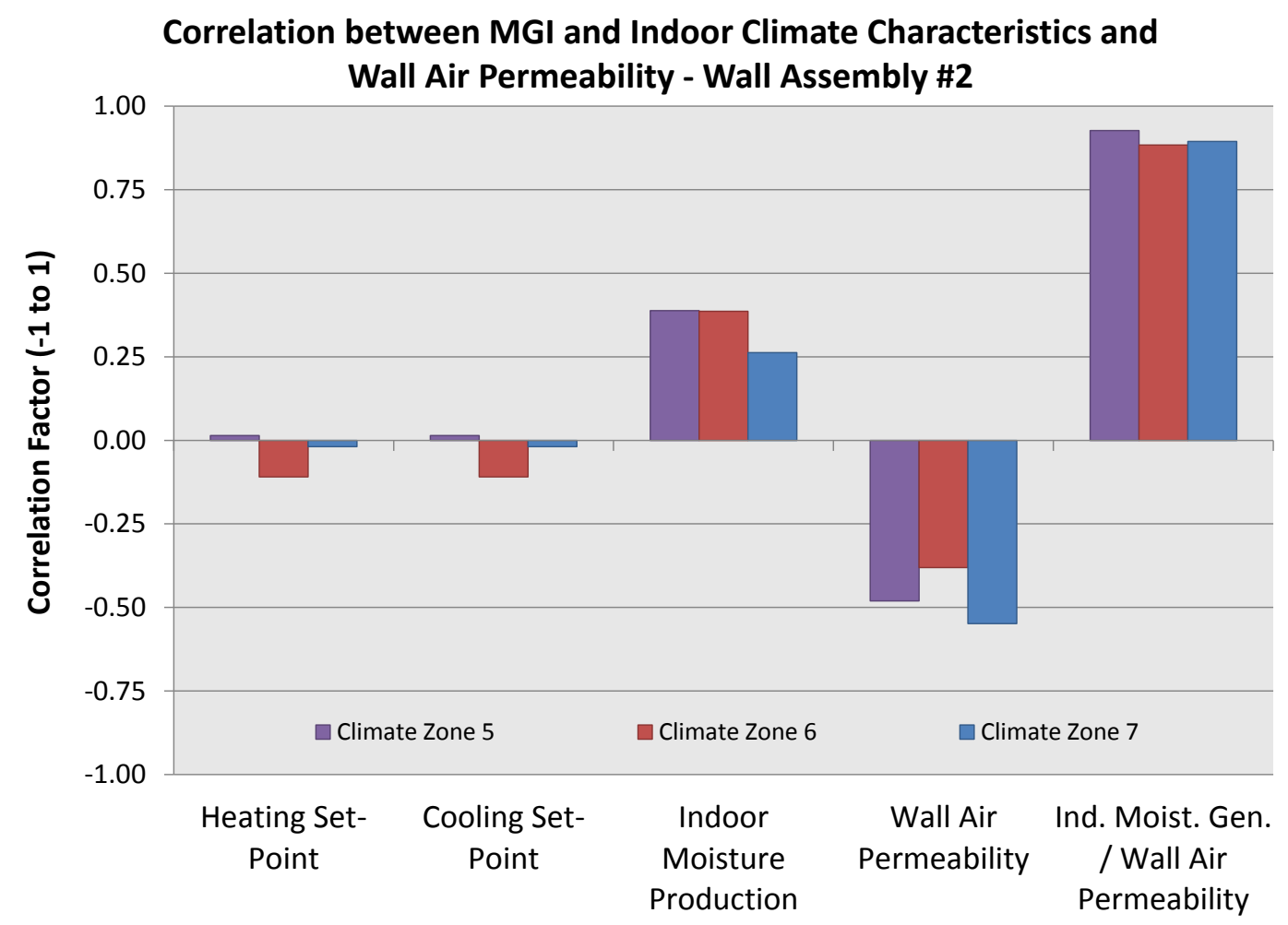

Figure 16. Correlation analyses for wall assembly 2 in the climate of Chicago, Minneapolis, and Anchorage. 


\section{CONCLUSIONS}

In this study, the hygrothermal performances of two different wall assemblies were evaluated, both complying with international building codes (IECC 2015 2014, IRC 2015). The first wall is considered a high- $R$ wall with insulation levels ranging up to a total of about R-31 in climate zone 6 . The second wall fulfills the insulation requirements in the latest building code: up to R-25 for climate zone 7 . Both walls were simulated in three different climate zones; the first wall design in climate zones 2,4, and 6 and the second wall in zones 5,6, and 7. For each climate zone, a total of 1,000 simulations were completed with probabilistically varying input parameters from laboratory chamber measurements, field data and existing and ongoing research; such as thermostat settings, indoor moisture generation, overall airtightness of the building, and air leakage resulting in moisture leaks. The simulation results were evaluated based on the MGI performance indicator (Ojanen, Peuhkuri et al. 2011), in which each simulated wall was evaluated as having either a low, moderate, or high risk of mold growth. Although MGI is an indicator of mold, it is not an indicator of indoor air quality and does not reveal the impact on moisture durability of the studied wall assemblies. However, having mold problems is a clear indicator of an increased risk of moisture durability issues.

An analysis of the first wall revealed that there would be a risk of mold issues if the wall were constructed in a hot and humid climate zone like Houston, Texas. In this climate, the thermostat set point for cooling was seen as the parameter most influencing the risk of mold growth. A lower indoor temperature for cooling creates a cooler exterior surface on the drywall, thus increasing the risk of high relative humidity levels. Obviously, the high $R$-value of the wall would ensure that the temperature of the drywall was close to that of the indoor environment. However, hot and humid outdoor air may travel to the inner surfaces of the wall, such as the drywall, and create moisture problems. Lower airtightness of the wall was also seen to increase the risk of mold. Therefore, the conclusions can be drawn that increasing insulation levels also increases the risk of moisture durability problems, and that the risk can be reduced by raising the thermostat setting for cooling and by making the wall more airtight.

For the second wall, two parameters have the largest impact on the MGI performance indicator: the amount of indoor moisture generated in the homes and the airtightness of the walls. However, what is seen as the most influential parameter by far is a combination of the two parameters, represented by a factor that is the ratio of indoor moisture generation to wall air permeability. With high indoor moisture generation and low wall air permeability (high airtightness), this ratio is high. If moisture generation is low and the wall is leaky, the ratio is low. As seen in the correlation analysis, this factor is greatly correlated with the risk of mold. For the studied wall design in climate zone 6 , the mold risk is low. However, in climate zones 5 and 7, the risks are significant. Unfortunately, the risk of mold increases as the air permeance of the wall decreases. This means that a more airtight wall will improve the energy efficiency but lead to a higher risk of moisture problems.

It is important to clarify that the risk of mold was evaluated at the most critical position inside the wall; therefore, it is impossible to estimate how widespread the mold growth would be. It is also relevant to make clear that, even if mold exists inside the wall, it is difficult to predict how much it will affect the quality of the indoor environment. 


\section{REFERENCES}

ANSI/ASHRAE (2013). Energy-Efficient Design of Low-Rise Residential Buildings - ANSI/ASHRAE 90.1-2013,. Atlanta, GA, American Society of Heating, Refrigerating and Air-conditioning Engineers, Inc.

ASCE/SEI 7-10 (2010). Minimum Design Loads for Buildings and Other Structures. ASCE/SEI 7-10, American Society of Civil Engineers.

ASHRAE 160 (2011). ANSI/ASHRAE Addendum a to Standard 160-2009 Criteria for Moisture-Control Design Analysis in Buildings. Atlanta, GA, American Society of Heating, Refrigerating and Airconditioning Engineers, Inc.

Booten, C. and P. Norton (2014). The Indoor Temperature and Humidity Study: Status and Preliminary Results. www.nrel.gov/publications, National Renewable Energy Laboratory.

Desmarais, G., D. Derome and P. Fazio (2000). "Mapping of air leakage in exterior wall assemblies." Journal of Building Physics 24:132-154.

Fox, M. (2014). Hygrothermal performance of highly insulated wood frame walls with air leakage: field measurements and simulations. Ryerson University, Toronto, Canada. M.A.Sc. Thesis.

Glass, S. (2013). Hygrothermal analysis of wood-framed wall assemblies in a mixed-humid climate. Madison, WI: US Department of Agriculture, Forest Service, Forest Products Laboratory. Research paper FPL-RP-675.

Hendron, R. and C. Engebrecht (2010). Building America Research Benchmark Definition, National Renewable Energy Laboratory.

HIRL (2013). Characterization of the Moisture Performance of Energy-Efficient and Conventional LightFrame Wood Wall Systems. Home Innovation Research Labs, Inc. Report \# 3329_11182013.

HIRL (2014). Moisture performance of walls in energy efficient homes. Home Innovation Research Labs. Report 5932.001_08142014.

Hukka, A. and H. A. Viitanen (1999). "A mathematical model of mould growth on wooden material." Wood Science and Technology 33.

Hun, D. and J. Atchley (2015). Air Leakage Rates in Typical Air Barrier Assemblies, Oak Ridge National Laboratory for the U.S. Department of Energy.

IECC 2015 (2014). International Energy Conservation Code - Residential Energy Efficiency. Country Club Hills, IL, USA, Internation Code Council, Inc. 
IRC, I. C. C.-. (2015). 2015 International Residential Code - For one- and two-family dwellings, International Code Council, Inc.

Künzel, H. M. (2012). Modeling Air Leakage in Hygrothermal Envelope Simulation. BEST 3 Conference, Atlanta, GA.

Künzel, H. M., D. Zirkelbach and B. Scfafaczek (2011). Vapour control design in wooden structures including moisture sources due air exfiltration. 9th Nordic Symposium on Building Physics - NSB 2011, Tampere, Finland.

Langmans, J., R. Klein and S. Roels (2012). "Hygrothermal risks of using exterior air barrier systems for highly insulated light weight walls: a laboratory investigation." Building and Environment 56: 192-202.

LBNL (2015). "Lawrence Berkeley National Laboratory - Residential Diagnostics Database." from http://resdb.lbl.gov/.

Lstiburek, J. (2006). "Understanding Air Barriers." ASHRAE Journal 47(7): 24-30.

Ojanen, T., R. Kohonen and K. Kumaran (1994). "Modeling heat, air and moisture transport through building materials and components." in: Trechsel, HR ed., Moisture Control in buildings, 1st ed. West Conshohocken, PA: ASTM International: 18-34. Chapter 2.

Ojanen, T., R. Peuhkuri, H. A. Viitanen, K. Lähdesmäki, J. Vinha and K. Salminen (2011). Classification of material sensitivity - New approach for mould growth modeling. 9th Nordic Symposium on Building Physics. Tampere, Finland.

Pallin, S. (2013). Risk Assessment of Hygrothermal Performance - Building Envelope Retrofit. Department of Civil and Environmental Engineering. Gothenburg, Sweden, Chalmers University of Technology. Doctoral thesis.

Pallin, S., D. Hun, R. jackson and M. kehrer (2014). Risk Assessment of Energy-Efficient Walls, ORNL/TM-2014/676, Building Technologies Research and Integration Center - Energy and Transportation Science Division, Oak Ridge National Laboratory, TN, USA.

RAP-RETRO (2011). "Annex 55 Reliability of Energy Efficient Building Retrofitting - Probability Assessment of Performance \& Cost (RAP-RETRO)." from http://www.ecbcs.org/annexes/annex55.htm.

RECS (2015). "Residential Energy Consumption Survey ". from http://www.eia.gov/consumption/residential/.

Straube, J. and J. Smegal (2012). Building America Special Research Project: High-R Walls Case Study Analysis. Building Science Corporation, Report 0903, prepared for the National Renewable Energy Laboratory. 
Viitanen, H. A., M. Krus, T. Ojanen, V. Eitner and D. Zirkelbach (2015). Mold Risk Classification Based on Comparative Evaluation of Two Established Growth Models. 6th International Building Physics Conference, IBPC 2015. 


\section{APPENDIX A}

Steady state 1D thermal conditions at any location inside a building component (e.g., wall, roof) can be described through a network analysis (Eq. [1]).

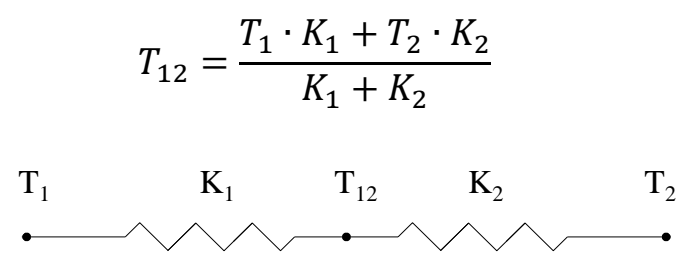

Here, $T$ is the temperature $\left({ }^{\circ} \mathrm{F}\right)$ and $K$ is the material thermal conductance $\left(\mathrm{Btu} /\left(\mathrm{h} \cdot{ }^{\circ} \mathrm{F}\right)\right) . T_{1}, T_{2}$ and $T_{12}$ are the temperatures of the outdoor air, indoor air, and at a point inside the building component (the air leakage path), respectively; while $K_{1}$ and $K_{2}$ are the thermal conductances of the materials between these points. In a steady state 1D thermal condition, air leakage can be included into Eq. (1) as a heat source or sink, $I(\mathrm{Btu} / \mathrm{h})$, as indicated in Eqs. (2) and (3)

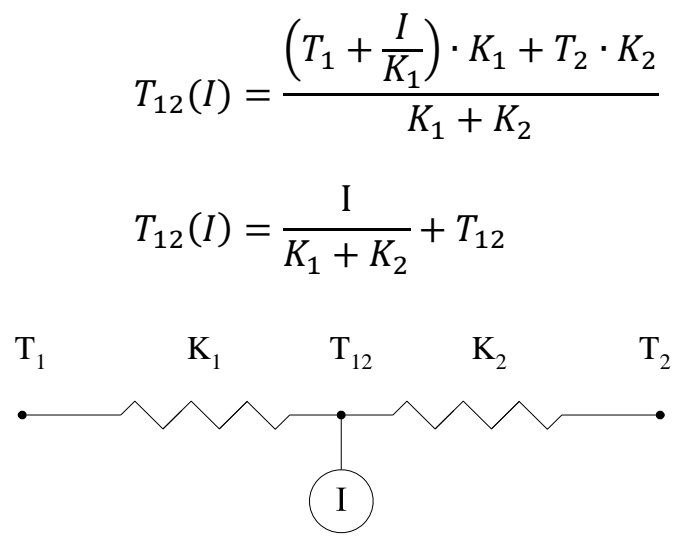

where $I$ is defined as

$$
I=\rho_{\text {air }} \cdot c_{\text {air }} \cdot\left(T_{2}-T_{12}(I)\right) \cdot Q
$$

Here, $\rho\left(\mathrm{lb} / \mathrm{ft}^{3}\right)$ and $c\left(\mathrm{Btu} /\left(\mathrm{lb} \cdot{ }^{\circ} \mathrm{F}\right)\right)$ are the density and specific heat capacity of the air, respectively, and $Q$ $\left(\mathrm{cfm}\right.$ or $\mathrm{ft}^{3} / \mathrm{s}$ ) is the air leakage rate. As seen in Eq. (4), $I$ is a function of $T_{12}(I)$, although, using Eq. (3) together with Eq. (4), the dependency can be avoided.

$$
I=\rho_{\text {air }} \cdot c_{\text {air }} \cdot\left(T_{2}-T_{12}\right) \cdot Q
$$

Air leakage is simulated in WUFI 1D and WUFI 2D as an air change rate (ACH) that originates from either the indoor or the outdoor environment, and is distributed uniformly over a defined length in 1D cases or as an area in 2Dl simulations. This approach complies with the method described in Eq. (2) and can be expected to estimate 1D heat and moisture transfer accurately. For 2D transfer, this approach is questionable, since the exchange of heat and moisture within an air leakage path is dependent on the path length, as illustrated in Figure 17. Therefore, a more appropriate 2D solution is considered in this work and applies as follows: 


$$
T(x)=T_{1}+\left(T_{2}-T_{1}\right) \cdot e^{\left(\frac{-x}{l_{c}}\right)}
$$

where $x(\mathrm{ft})$ is the distance between the entry point of the air into the air leakage path and the point of evaluation, and $l_{c}(\mathrm{ft})$ is the characteristic length per

$$
l_{c}=\frac{\rho_{\text {air }} \cdot c_{\text {air }} \cdot Q}{L_{\text {surf }} \cdot K}
$$

Here, $L_{\text {surf }}(\mathrm{ft})$ is the surface length or the perimeter of the cross section through the air leakage path, and $K$ is the effective thermal conductance of the materials surrounding the air leakage path (in this case $\left.K_{1}+K_{2}\right)$.

Figure 17 compares the solutions from Eqs. (2) and (6), and indicates a large discrepancy between their results. The thermal conductances and geometrical characteristics used in these estimates belong to those from the test specimen described in Section 3.3. Since Eq. (6) is dependent on the distance that the air has traveled within the leakage path, solutions are presented at five different locations. As seen in Figure 17, when air flows at a rate of $5 \mathrm{cfm}$, Eq. (2) predicts a constant air temperature of $57^{\circ} \mathrm{F}$ along the airflow path. In contrast, Eq. (4) indicates that temperatures will vary from 51 to $64^{\circ} \mathrm{F}$ at distances that range from 1 to $8 \mathrm{ft}$ from the air entry point.

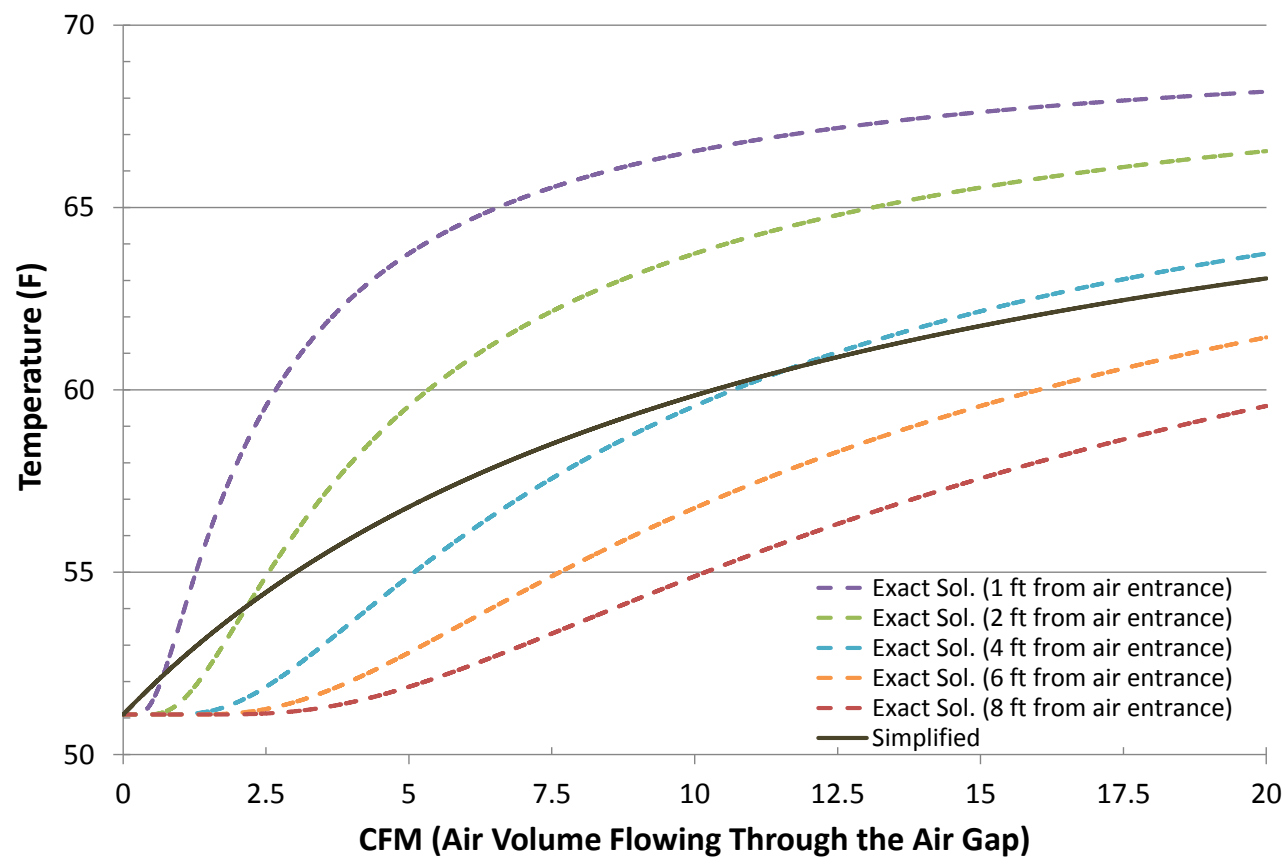

Figure 17. A comparison between 1D and 2D steady-state solutions for heat exchange in an air channel.

As was previously discussed, WUFI 1D and WUFI 2D distribute the air leakage uniformly over a defined path or area. Since Eq. (2) is not valid for 2D air leakage paths, the suggested approach is to create a correction factor, $\eta$, which allows the solution of Eq. (2) to match that of Eq. (6). This correction factor can then be incorporated into WUFI through an $\mathrm{ACH}$, which is derived from the adjusted source/sink, $I_{\eta}$, expressed as

$$
I_{\eta}=\eta(x, Q) \cdot I
$$


where $\eta$ is a function of both the distance into the air leakage path and the air flow rate.

If the solution of Eq. (2) includes $I_{\eta}$ instead of $I$, the following can be stated under the assumption that

$$
\begin{aligned}
& T(x)=T_{12}\left(I_{\eta}\right) \\
& T(x)=\frac{\left(T_{1}+\frac{I_{\eta}}{K_{1}}\right) \cdot K_{1}+T_{2} \cdot K_{2}}{K_{1}+K_{2}}
\end{aligned}
$$

$I_{\eta}$ can be expressed as

$$
I_{\eta}=\left(\frac{T(x) \cdot(K)-T_{2} \cdot K_{2}}{K_{1}}-T_{1}\right) \cdot K_{1}
$$

where $K=K_{1}+K_{2}$. Finally, $\eta$ can be derived using Eqs. (4), (8), and (11), resulting in

$$
\eta(x, Q)=\frac{\left(\frac{T(x) \cdot(K)-T_{2} \cdot K_{2}}{K_{1}}-T_{1}\right) \cdot K_{1}}{\rho_{\text {air }} \cdot c_{\text {air }} \cdot\left(T_{2}-T_{12}(I)\right) \cdot Q}
$$

In accordance with Eqs. (4) and (8), $I_{\eta}$ can be expressed as a function of $x$ and $\mathrm{ACH}$ :

$$
Q=A C H \cdot \frac{V}{3600}
$$

where $Q\left(\mathrm{ft}^{3} / \mathrm{s}\right)$ and $V\left(\mathrm{ft}^{3}\right)$ is the air volume of the air leakage path, and which can be used as an input for air leakage in WUFI.

$$
I_{\eta}=A C H_{\eta} \cdot \frac{V}{3600} \cdot \rho_{\text {air }} \cdot c_{\text {air }} \cdot\left(T_{2}-T_{12}(I)\right)
$$

where

$$
A C H_{\eta}=\eta(x, Q) \cdot A C H
$$

In conclusion, $\mathrm{ACH}_{\eta}$ is the corrected air change rate that is used as an input in WUFI. In other words, the correction factor $\eta$ is used to let the 1D air leakage solution of WUFI represent a 2D solution.

Noteworthy is that in the present study, $\eta$ was calculated only as a function of $x$ and $Q$ because preliminary analyses indicated that changes in $T_{1}, T_{2}, K_{1}$ and $K_{2}$ have minimal effects on the correction factor.

An analogous procedure can be followed with 2D moisture transfer, as seen in Eq. (16)

$$
v(x)=v_{1}+\left(v_{2}-v_{1}\right) \cdot e^{\left(\frac{-x}{l_{c_{v}}}\right)}
$$

where $v\left(\mathrm{lb} / \mathrm{ft}^{3}\right)$ is the moisture content of the air along the leakage path, $l_{c_{v}}(\mathrm{ft})$ is the characteristic length for moisture transfer, and $K_{v}(\mathrm{ft} / \mathrm{s})$ is the water vapor transport conductance (Hagentoft 2001). 


$$
l_{c_{v}}=\frac{Q}{L_{s u r f} \cdot K_{v}}
$$

Eqs. (12) and (13) can be used in conjunction with the procedure described above to estimate moisturerelated correction factors and sources. However, as was seen in Figure 1 of this report, the length of the path has a greater effect on heat exchange than on moisture exchange. Therefore, efforts were focused on generating correction factors for the temperature analyses rather than the moisture analyses. 


\section{APPENDIX B.}

In the first report to present the $\eta$-method (Pallin, Hun et al. 2014), the validations were based on comparisons between WUFI 2D and measurements made inside the Heat, Air and Moisture (HAM) penetration chambers at Oak Ridge National Laboratory (Figure 18).

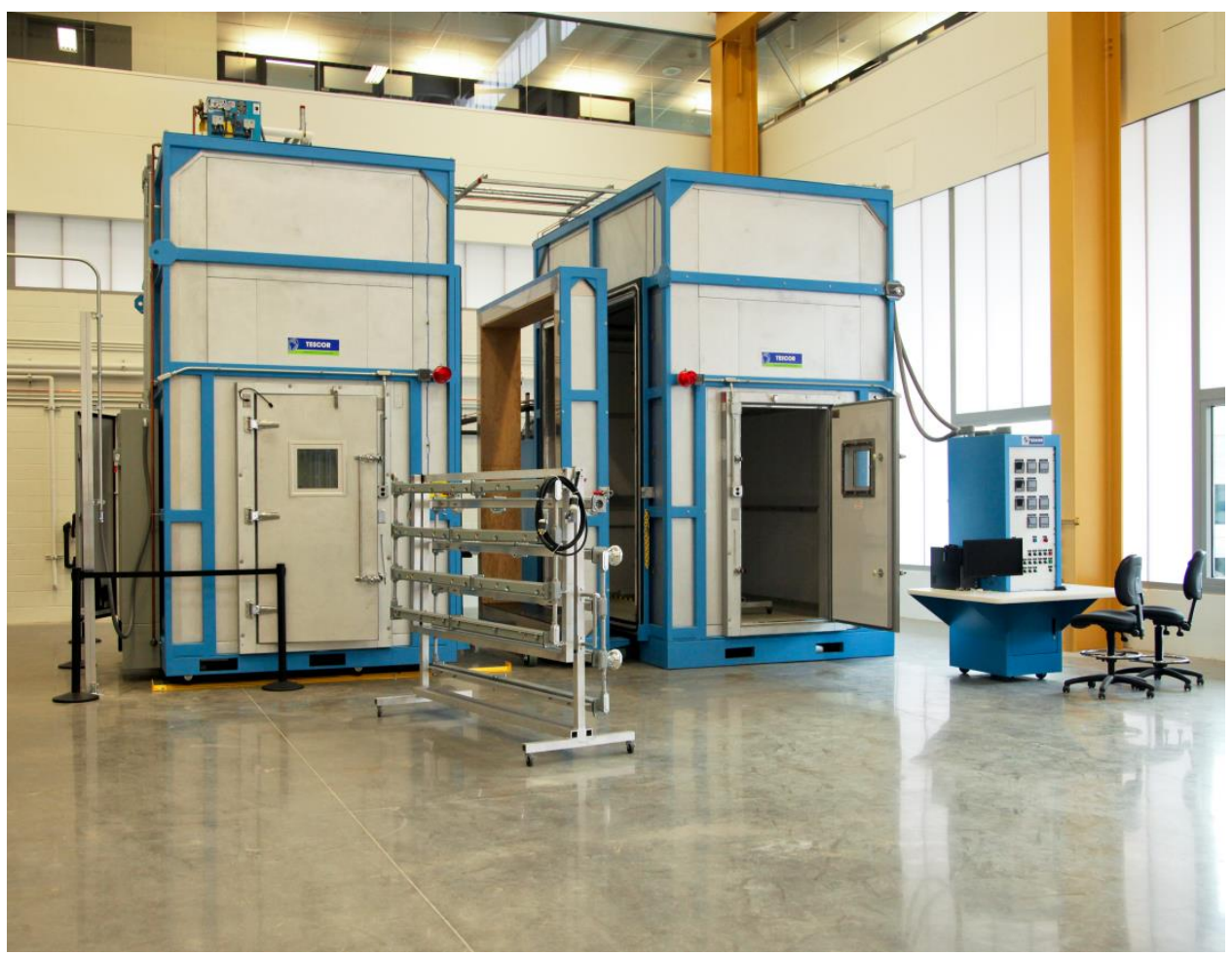

Figure 18. HAM penetration chambers at Oak Ridge National Laboratory.

A wall specimen was constructed and temperature and relative humidity were measured at several locations inside the wall. These locations were then evaluated against simulated results using the proposed $\eta$-method. By comparing the variations in temperature and relative humidity under different climate conditions, the $\eta$-method was validated against measurements (see Figure 19).

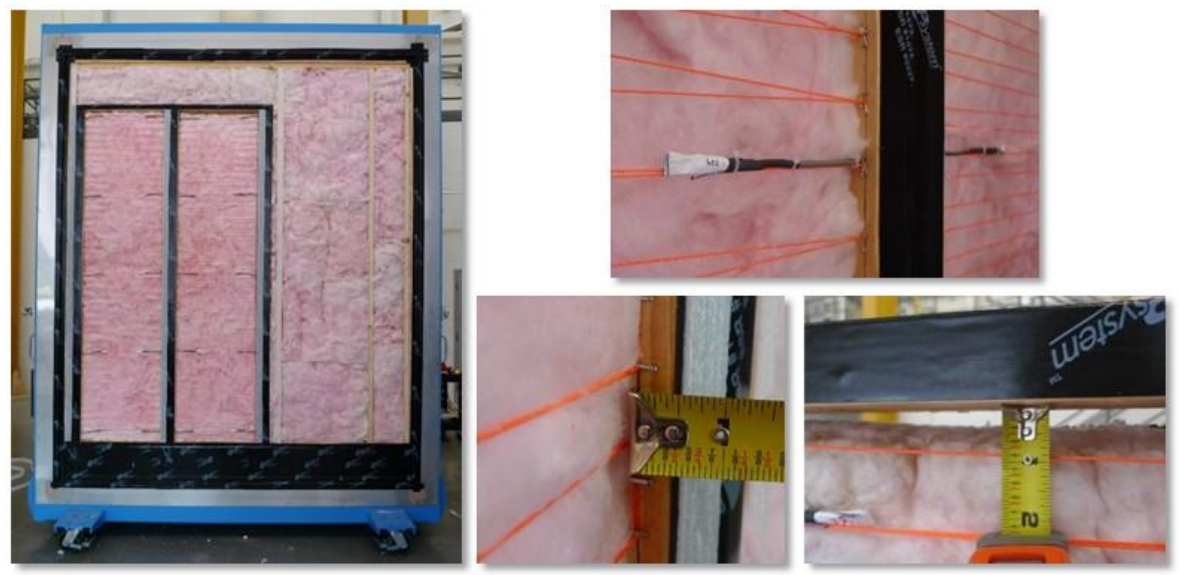

Figure 19. Wall specimen with thermocouples and relative humidity sensors located at multiple points. 
Despite a good agreement between measurements and simulations, continuous efforts have been made to improve the methodology. The previous approach did not take into account the heat and moisture exchange that occurs between the air and the surrounding materials before the air hits the potential condensation plane. This part of the air leakage path is illustrated in Figure 1 and Figure 2 of this report as the area between the arrow representing incoming air and the blue marker. The effect of this improvement was studied by comparing simulation result with previous measurements; as seen in Figure 20, the measured and simulated conditions match well.

\section{$\underline{\text { Temperatures inside an air leakage channel at 40Pa pressure difference }}$}

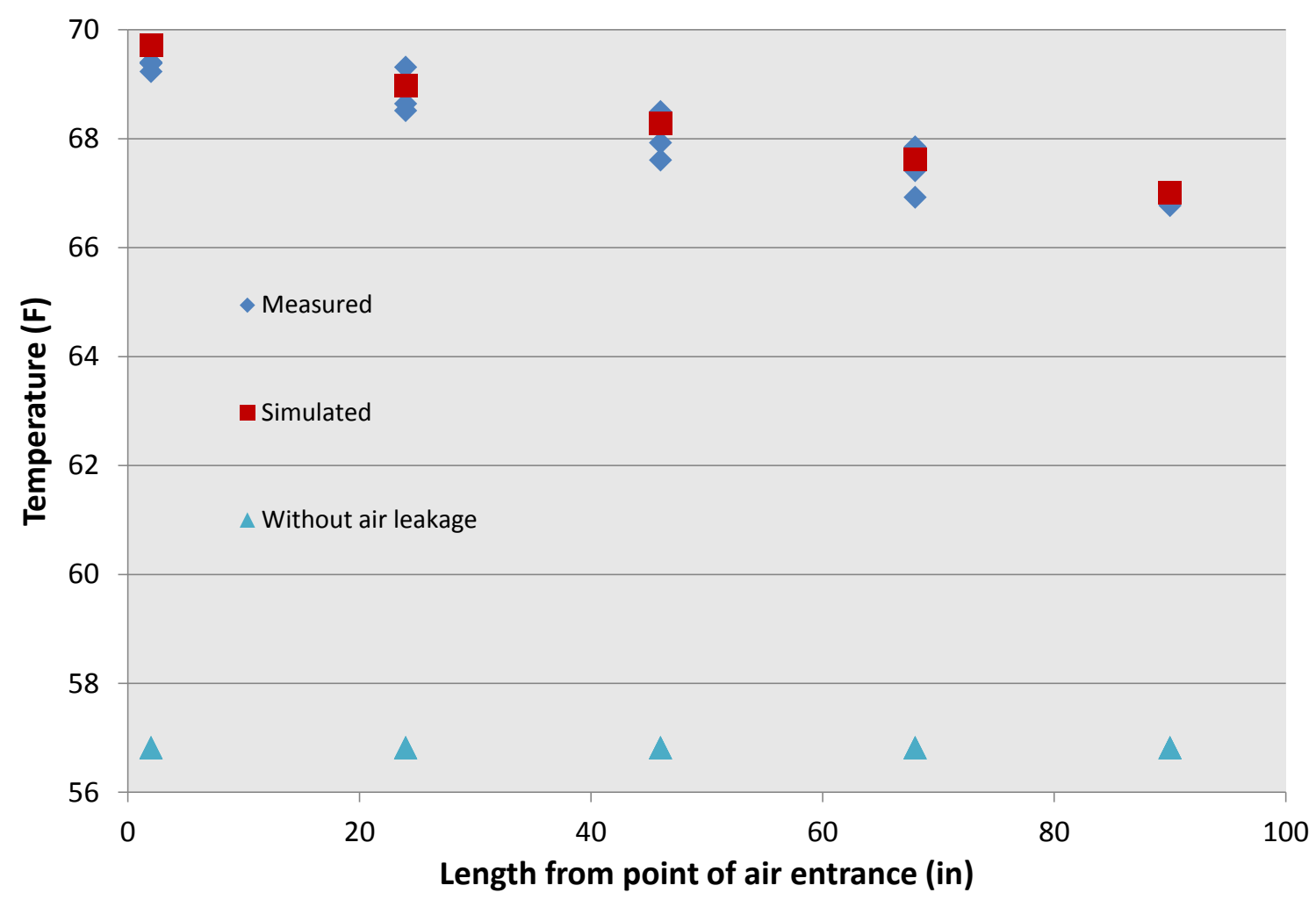

Figure 20. Validation of the proposed $\eta$-method agrees well with measurements. The comparison was made at five locations inside an air leakage path. 